\title{
论 文
}

\section{中国致密砂岩大气田的稳定碳氢同位素组成特征}

\author{
戴金星*，倪云燕，胡国艺，黄士鹏，廖凤蓉，于聪，龚德瑜，吴伟 \\ 中国石油勘探开发研究院，北京 100083 \\ *E-mail: djx@ @etrochina.com.cn
}

收稿日期: 2013-04-20; 接受日期: 2013-07-20; 网络版发表日期: 2014-02-28

摘要至 2010 年底中国共发现 15 个致密砂岩大气田, 分布在鄂尔多斯盆地、四川盆地和塔 里木盆地. 这些气田 2010 年气产量和总储量分别为 $222.5 \times 10^{8}$ 和 $28657 \times 10^{8} \mathrm{~m}^{3}$, 分别占全国的 $23.5 \%$ 和 $37.3 \%$, 是中国产量和储量的主要组成部分. 根据 81 个气样分析, 中国致密砂岩大气 田稳定碳氢同位素组成主要特征为: (1) 综合 $\delta^{13} \mathrm{C}_{1}-\delta^{13} \mathrm{C}_{2}-\delta^{13} \mathrm{C}_{3}$ 图版, $\delta^{13} \mathrm{C}_{1}-\mathrm{C}_{1} / \mathrm{C}_{2+3}$ 图版和 $\delta^{13} \mathrm{C}_{1}-\delta^{13} \mathrm{C}_{2}$ 回归线分析, 中国致密砂岩大气田的天然气为来自含煤岩系的煤成气; (2) 原生烷 烃气随分子中碳数顺增, 碳氢同位素值随之变重, 即 $\delta^{13} \mathrm{C}_{1}<\delta^{13} \mathrm{C}_{2}<\delta^{13} \mathrm{C}_{3}<\delta^{13} \mathrm{C}_{4}$ 和 $\delta^{2} \mathrm{H}_{1}<\delta^{2} \mathrm{H}_{2}<$ $\delta^{2} \mathrm{H}_{3}$; (3) $\delta^{13} \mathrm{C}_{2}-\delta^{13} \mathrm{C}_{1}, \delta^{13} \mathrm{C}_{3}-\delta^{13} \mathrm{C}_{1}$ 和 $\delta^{2} \mathrm{H}_{2}-\delta^{2} \mathrm{H}_{1}, \delta^{2} \mathrm{H}_{3}-\delta^{2} \mathrm{H}_{1}$ 随 $R_{0}(\%)$ 和 $\mathrm{C}_{1} / \mathrm{C}_{1 \sim 4}$ 值渐增而减小; (4) 碳 氢同位素倒转成因有 7 种, 中国致密砂岩大气田碳氢同位素倒转主要是多期成藏充注所致.

关键词

致密砂岩

大气田

碳氢同位素

煤成气

中国
非常规气的研究、勘探和开发日益被重视. 非常 规气主要包括致密砂岩气、页岩气、煤层气和天然气 水合物. 在世界产气大国中, 非常规气勘探开发取得 显著进展和效益的是致密砂岩气, 世界第一产气大 国一一美国 2010 年致密砂岩气产量占该国总产量的 $26 \%$ ，而页岩气只占 $23 \%$ (U.S.EIA，2012); 中国致密 砂岩气 2010 年产量为 $233 \times 10^{8} \mathrm{~m}^{3}$, 占全国总产量的 24.6\%(Dai 等, 2012a), 其中致密砂岩大气田年产量占 全国的 $23.5 \%$, 故中美两国非常规气中以致密砂岩气 的产量为最多者. 致密砂岩气的储量也占有重要地 位, 美国储量排名前 100 的气藏中有 58 个是致密砂 岩气藏(Baihly 等, 2007). 中国至 2010 年底, 致密砂 岩气探明地质储量 $30109 \times 10^{8} \mathrm{~m}^{3}$, 占全国总储量的 39.2\%(Dai 等, 2012a). 因此, 致密砂岩气的勘探开发 对现今一些天然气大国和未来世界天然气工业持续 发展有很大的意义.
与致密砂岩气的勘探开发相比, 致密砂岩气的 地球化学研究则相对逊色, 特别是对其气源追踪, 鉴 别和成藏有重要作用的稳定碳氢同位素研究薄弱. 目前仅对西加拿大盆地两个深盆气气田致密砂岩烷 烃气的碳同位素(James, 1990)和 Appalachian 盆地北 部深盆气的稳定碳氢同位素(Burruss 和 Laughrey, 2010)组成作了研究. 本文将对中国 15 个致密砂岩大 气田烷烃气的碳, 氢同位素作系统研究, 以推动和丰 富致密砂岩气这方面的进展.

\section{1 中国致密砂岩大气田}

根据中国国家能源局标准(SY/T6832-2011)(中国 国家能源局，2011)，把覆压基质渗透率小于或等于 $0.1 \times 10^{-3} \mu \mathrm{m}^{2}$ 砂岩称为致密砂岩, 这与世界上许多学 者的致密砂岩标准是一致的(Elkins, 1978; Spencer,

中文引用格式: 戴金星, 倪云燕, 胡国艺, 等. 2014. 中国致密砂岩大气田的稳定碳氢同位素组成特征. 中国科学: 地球科学,44: 563-578

英文引用格式: Dai J X, Ni Y Y, Hu G Y, et al. 2014. Stable carbon and hydrogen isotopes of gases from the large tight gas fields in China. Science China: Earth Sciences, 57: 88-103, doi: 10.1007/s11430-013-4701-7 
1985; Holditch, 2006). 以此标准衡量, 美国落基山盆 地群中众多深盆气藏的储层砂岩属于致密砂岩, 所 以 Surdam(1997)把深盆气藏纳入致密砂岩气藏之内.

目前, 在中国鄂尔多斯盆地、四川盆地、塔里木 盆地和渤海湾盆地均发现了致密砂岩气田(藏)(Yang 等, 2008; 杨华等, 2012; Dai 等, 2005a, 2012a, 2012b; Zhang 等, 2009; Zou 等, 2011; 许化政, 1991; 曾大乾 等, 2003). 中国第一个致密砂岩气田是在四川盆地中 坝须家河组二段气藏 $\left(\mathrm{T}_{3} x^{2}\right), 1973$ 年发现并已投产多 年. 根据 1435 个岩芯统计, 该气藏砂岩平均孔隙度 为 $6.4 \%$; 根据 1319 个岩芯统计, 渗透率平均为 $0.0804 \times 10^{-3} \mu \mathrm{m}^{2}$ (刘宝和, 2011). 按中国标准把探明 天然气储量大于 $300 \times 10^{8} \mathrm{~m}^{3}$ 的气田称为大气田 $($ 表 1 ; 图 1), 中国至 2010 年底共发现致密砂岩大气田 15 个 (Dai 等, 2012a). 表 1 中一些大气田渗透率大于 $0.1 \times 10^{-3} \mu \mathrm{m}^{2}$, 如中国最大致密砂岩大气田苏里格气 田, 3 个气层 1434 个样品平均渗透率为 $1.284 \times 10^{-3}$ $\mu \mathrm{m}^{2}$, 其中山 $1\left(\mathrm{P}_{1} s^{1}\right)$ 段砂岩产层平均渗透率 $0.60 \times 10^{-3}$ $\mu \mathrm{m}^{2}$ (邹才能等, 2009), 超过致密砂岩 $0.1 \times 10^{-3} \mu \mathrm{m}^{2}$ 的 渗透率标准, 但根据砂岩大面积致密化, 成藏和气水 分布研究, 众多学者认为苏里格气田的三套气层均 属致密砂岩(Yang 等, 2008; 杨华等, 2012; 杨涛等, 2012; 张国生等, 2012), 渗透率超标, 是由甜点区少 量渗透率高的样品所致, 实际上砂岩主流渗透率都 小于 $0.1 \times 10^{-3} \mu \mathrm{m}^{2}$, 童晓光等(2012)指出苏里格气田 和四川盆地须家河组 $\left(\mathrm{T}_{3} x\right)$ 砂岩产层的覆压渗透率小 于 $0.1 \times 10^{-3} \mu \mathrm{m}^{2}$ 的占样品比例 $80 \%$ 92\%；杨华等 (2012)指出鄂尔多斯盆地上古生界砂岩产气层, 在覆 压条件下，基质渗透率小于 $0.1 \times 10^{-3} \mu \mathrm{m}^{2}$; 张国生等 (2012)指出四川盆地须家河组天然气主力产层须二 段 $\left(\mathrm{T}_{3} x^{2}\right)$, 须四段 $\left(\mathrm{T}_{3} x^{4}\right)$ 和须六段 $\left(\mathrm{T}_{3} x^{6}\right)$ 砂岩孔隙度 $6 \% \sim 10 \%$, 渗透率为 $0.01 \times 10^{-3} \sim 0.5 \times 10^{-3} \mu \mathrm{m}^{2}$, 均小于 $0.1 \times 10^{-3} \mu \mathrm{m}^{2}$, 所以属致密砂岩大气田. 中国致密砂 岩大气田在天然气工业中起着主要的作用, 2010 年其

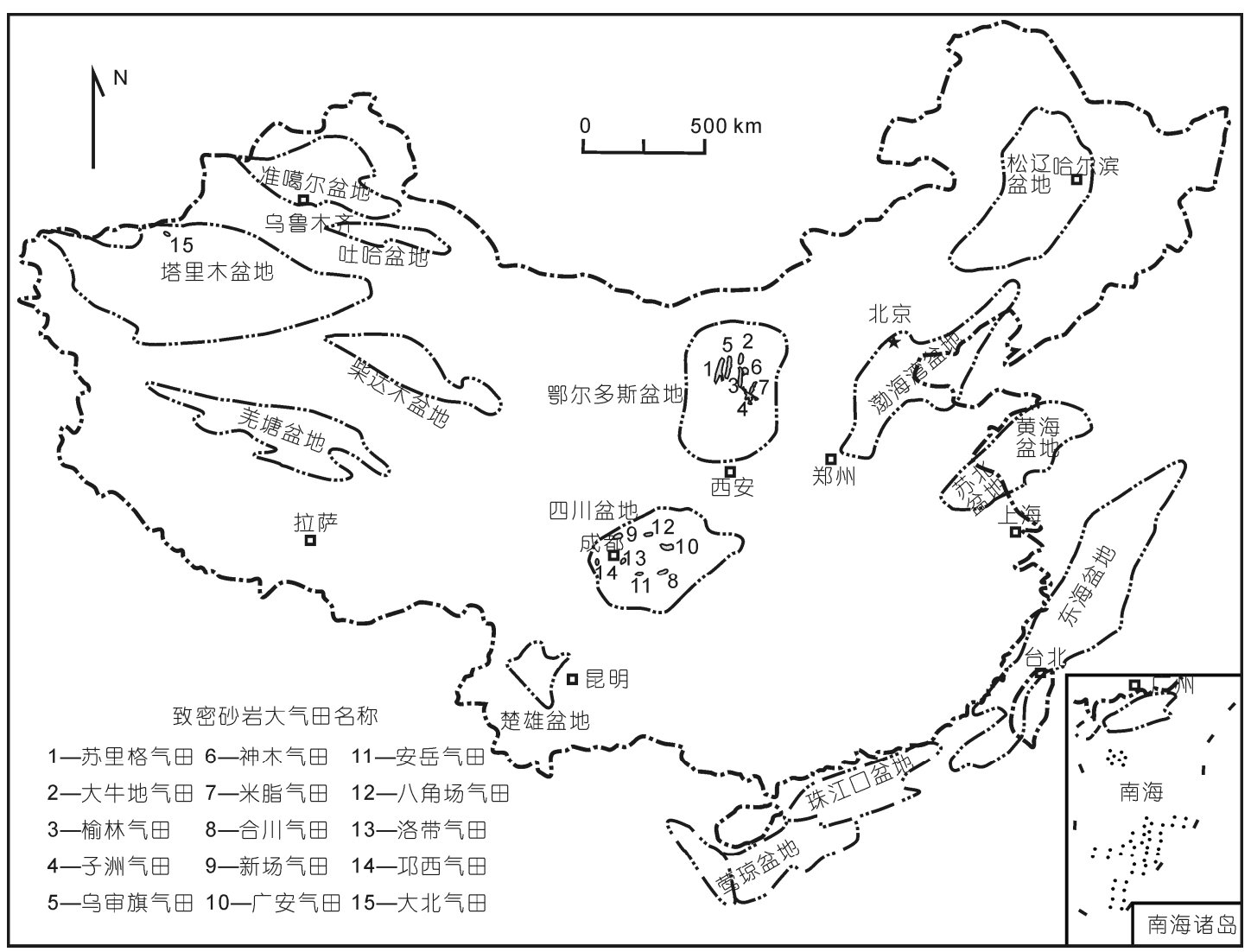

图 1 中国致密砂岩大气田分布图(Dai 等, 2012a) 
表 1 中国致密砂岩大气田基础数据 ${ }^{\text {a) }}$

\begin{tabular}{|c|c|c|c|c|c|c|c|}
\hline \multirow{2}{*}{ 盆地 } & \multirow{2}{*}{ 气田 } & \multirow{2}{*}{ 主要产层 } & \multirow{2}{*}{$\begin{array}{l}\text { 探明储量 } \\
\left(\times 10^{8} \mathrm{~m}^{3}\right)\end{array}$} & \multirow{2}{*}{$\begin{array}{c}\text { 年产量 } \\
\left(\times 10^{8} \mathrm{~m}^{3}\right)\end{array}$} & \multirow{2}{*}{ 平均孔隙度 $(\%)$} & \multicolumn{2}{|c|}{ 渗透率 $\left(10^{-3} \mu \mathrm{m}^{2}\right)$} \\
\hline & & & & & & 范围 & 平均值 \\
\hline \multirow{7}{*}{$\begin{array}{l}\text { 鄂尔 } \\
\text { 多斯 }\end{array}$} & 苏里格 & $\mathrm{P}_{2} s h, \mathrm{P}_{2} x, \mathrm{P}_{1} s^{1}$ & 11008.2 & 104.75 & $7.163(1434)$ & $0.001 \sim 101.099$ & $1.284(1434)$ \\
\hline & 大牛地 & $\mathrm{P}, \mathrm{C}$ & 3926.8 & 22.36 & $6.628(4068)$ & $0.001 \sim 61.000$ & $0.532(4068)$ \\
\hline & 榆林 & $\mathrm{P}_{1} s^{2}$ & 1807.5 & 53.3 & $5.630(1200)$ & $0.003 \sim 486.000$ & $4.744(1200)$ \\
\hline & 子洲 & $\mathrm{P}_{2} x$ & 1152.0 & 5.87 & $5.281(1028)$ & $0.004 \sim 232.884$ & $3.498(1028)$ \\
\hline & 乌审旗 & $\mathrm{P}_{2} s h, \mathrm{P}_{2} x, \mathrm{O}^{1}$ & 1012.1 & 1.55 & $7.820(689)$ & $0.001 \sim 97.401$ & $0.985(687)$ \\
\hline & 神木 & $\mathrm{P}_{1} t^{1}, \mathrm{P}_{1} s, \mathrm{P}_{2} x$ & 935.0 & 0 & $4.712(187)$ & $0.004 \sim 3.145$ & $0.353(187)$ \\
\hline & 米脂 & $\mathrm{P}_{1} s^{1}, \mathrm{P}_{2} x, \mathrm{P}_{2} s h$ & 358.5 & 0.19 & $6.180(1179)$ & $0.003 \sim 30.450$ & $0.655(1179)$ \\
\hline \multirow{7}{*}{ 四川 } & 合江 & $\mathrm{T}_{3} x$ & 2299.4 & 7.46 & 8.45 & & 0.313 \\
\hline & 新场 & $\mathrm{J}_{3}, \mathrm{~T}_{3} x$ & 2045.2 & 16.29 & $12.31(>1300)$ & & $2.560(>1300)$ \\
\hline & 广安 & $\mathrm{T}_{3} x$ & 1355.6 & 2.79 & 4.2 & & 0.35 \\
\hline & 安岳 & $\mathrm{T}_{3} x$ & 1171.2 & 0.74 & 8.7 & & 0.048 \\
\hline & 八角场 & $\mathrm{J}, \mathrm{T}_{3} x$ & 351.1 & 1.54 & $\mathrm{~T}_{3} x^{4}$ 平均 7.93 & & 0.58 \\
\hline & 洛带 & $\mathrm{J}_{3}$ & 323.8 & 2.83 & 11.80(926) & & $0.732(814)$ \\
\hline & 邛西 & $\mathrm{J}, \mathrm{T}$ & 323.3 & 2.65 & $\mathrm{~T}_{3} x^{4}$ 平均 3.29 & & 0.0636 \\
\hline 塔里木 & 大北 & $\mathrm{K}$ & 587.0 & 0.22 & $2.6295)$ & & $0.036(5)$ \\
\hline
\end{tabular}

a) 据文献(Dai 等, 2012a)简化

探明天然气地质储量和产量 (表 1) 分别占全国的 $37.3 \%$ 和 $23.5 \%$. 苏里格致密气田是中国储量和产量 最大气田, 2011 年产天然气 $137 \times 10^{8} \mathrm{~m}^{3}$ (杨华等, 2012).

\section{2 样品和分析方法}

在鄂尔多斯, 四川以及塔里木盆地采集致密砂 岩大气田 81 个气样, 基本的地球化学数据见表 2 , 样 品测试分析均在中国石油勘探开发研究院廊坊分院 测定.

天然气组分分析采用 HP 6890 型气相色谱仪. 单 个烃类气体组分通过毛细柱分离(Plot $\mathrm{A}_{2} \mathrm{O}_{3} 50 \mathrm{~m} \times$ $0.53 \mathrm{~mm}$ ). 通过 2 个毛细柱分离稀有气体(Plot $5 \AA$ 分 子笁 $30 \mathrm{~m} \times 0.53 \mathrm{~mm}$, Plot Q $30 \mathrm{~m} \times 0.53 \mathrm{~mm})$. 气相色 谱仪炉温首先设定在 $30^{\circ} \mathrm{C}$ 保持 $10 \mathrm{~min}$, 然后以 $10^{\circ} \mathrm{C} /$ $\min$ 的速率升高到 $180^{\circ} \mathrm{C}$.

天然气碳同位素分析采用 Delta S GC/C/IRMS 同 位素质谱仪. 气体组分通过气相色谱仪分离, 然后转 化为 $\mathrm{CO}_{2}$ 注入到质谱仪. 单个烷烃气组分 $\left(\mathrm{C}_{1} \sim \mathrm{C}_{5}\right)$ 和 $\mathrm{CO}_{2}$ 通过色谱柱分离(Plot Q $30 \mathrm{~m}$ ), 色谱柱升温过程 为 $35 \sim 80^{\circ} \mathrm{C}$ (升温速率 $8^{\circ} \mathrm{C} / \mathrm{min}$ ), 一直到 $260^{\circ} \mathrm{C}$ (升温速 率 $5^{\circ} \mathrm{C} / \mathrm{min}$ ), 在最终温度保持炉温 $10 \mathrm{~min}$, 一个样品 分析 3 次. 稳定碳同位素值采用 VPDB 标准, 符号采
用 $\delta$, 单位为 $\% o$, 分析精度为 $\pm 0.5 \%$ 。

烷烃气氢同位素测试采用装备有 Ultra TM 色谱 仪的 MAT 253 同位素质谱仪测定. 载气为氦气, 色 谱柱为 HP-PLOT $\mathrm{Q}$ 毛细色谱柱 $(30 \mathrm{~m} \times 0.32 \mathrm{~mm} \times 20$ $\mu \mathrm{m})$, 流速为 $1.4 \mathrm{~mL} / \mathrm{min}$. 进口温度设定为 $180^{\circ} \mathrm{C}$, 甲 烷氢同位素测定时采用分馏注入模式(分流比为 1:7). 色谱升温程序: 初始温度为 $40^{\circ} \mathrm{C}$, 恒温 $5 \mathrm{~min}$, 以 $5^{\circ} \mathrm{C} /$ $\min$ 速度从 $40^{\circ} \mathrm{C}$ 程序升温到 $80^{\circ} \mathrm{C}$, 随后以 $5^{\circ} \mathrm{C} / \mathrm{min}$ 程 序升温至 $140^{\circ} \mathrm{C}, 30^{\circ} \mathrm{C}$ 程序升温至 $260^{\circ} \mathrm{C}$. 反应炉中的 温度为 $1450^{\circ} \mathrm{C}$. 天然气组分转化成 $\mathrm{C}$ 和 $\mathrm{H}_{2}, \mathrm{H}_{2}$ 被带 进质谱仪来测定氢同位素组成. 氢同位素测试采用 VSMOW 标准, 符号采用 $\delta$, 单位为 $\%$, 氢同位素测 试精度为 $\pm 3 \%$. 实验所用的碳氢同位素标样 NG1(煤 成气)和 NG3(油型气)由中国石油勘探开发研究院廊 坊分院以及国外著名实验室进行过校正(Dai 等, 2012c), 并采用两点校正法与国家标样进行了校正 (Coplen 等, 2006).

\section{3 烷烃气稳定碳同位素组成特征}

表 2 为中国 15 个致密砂岩大气田, 81 个气样烷 烃气稳定碳同位素 $\delta^{13} \mathrm{C}_{1 \sim 4}$ 分析成果, 由表 2 可得如下 特征. 
戴金星等: 中国致密砂岩大气田的稳定碳氢同位素组成特征

表 2 鄂尔多斯、四川和塔里木盆地致密砂岩大气田天然气组分、稳定碳和氢同位素组成

\begin{tabular}{|c|c|c|c|c|c|c|c|c|c|c|c|c|c|c|c|c|c|c|c|}
\hline \multirow{2}{*}{ 盆地 } & \multirow{2}{*}{ 气田 } & \multirow{2}{*}{ 序号 } & \multirow{2}{*}{ 井 } & \multirow{2}{*}{ 地层 } & \multicolumn{8}{|c|}{ 组分(vol\%) } & \multicolumn{4}{|c|}{$\delta^{13} \mathrm{C}(\%, \mathrm{VPDB})$} & \multicolumn{3}{|c|}{$\delta^{2} \mathrm{H}(\% o$, VSMOW $)$} \\
\hline & & & & & $\mathrm{CH}_{4}$ & $\mathrm{C}_{2} \mathrm{H}_{6}$ & $\mathrm{C}_{3} \mathrm{H}_{8}$ & $\mathrm{iC}_{4}$ & $\mathrm{nC}_{4}$ & $\mathrm{C}_{1 \sim 4}$ & $\mathrm{CO}_{2}$ & $\mathrm{~N}_{2}$ & $\delta \mathrm{C}_{1}$ & $\delta \mathrm{C}_{2}$ & $\delta \mathrm{C}_{3}$ & $\delta \mathrm{C}_{4}$ & $\delta^{2} \mathrm{H}_{1}$ & $\delta^{2} \mathrm{H}_{2}$ & $\delta^{2} \mathrm{H}_{3}$ \\
\hline \multirow{39}{*}{ 鄂尔多斯 } & \multirow{18}{*}{ 苏里格 } & 1 & 苏 21 & $\mathrm{P}_{1} s, \mathrm{P}_{2} x$ & 92.39 & 4.48 & 0.83 & 0.13 & 0.14 & 97.97 & 0.99 & 0.68 & -33.4 & -23.4 & -23.8 & -22.7 & -194 & -167 & -163 \\
\hline & & 2 & 苏 53 & $\mathrm{P}_{1} s, \mathrm{P}_{2} x$ & 86.05 & 8.36 & 2.17 & 0.37 & 0.44 & 97.39 & 1.13 & 0.72 & -35.6 & -25.3 & -23.7 & -23.9 & -202 & -165 & -160 \\
\hline & & 3 & 苏 75 & $\mathrm{P}_{2} x$ & 92.47 & 3.92 & 0.66 & 0.11 & 0.11 & 97.27 & 1.30 & 1.10 & -33.2 & -23.8 & -23.4 & -22.4 & -194 & -163 & -157 \\
\hline & & 4 & 苏 76 & $\mathrm{P}_{1} s, \mathrm{P}_{2} x$ & 86.41 & 8.37 & 2.33 & 0.39 & 0.51 & 98.01 & 0.13 & 1.21 & -35.1 & -24.6 & -24.4 & -24.4 & -203 & -165 & -161 \\
\hline & & 5 & 苏 95 & $\mathrm{P}_{2} x$ & 92.24 & 3.95 & 0.66 & 0.11 & 0.11 & 97.07 & 1.64 & 1.00 & -32.5 & -23.9 & -24.0 & -22.7 & -193 & -167 & -160 \\
\hline & & 6 & 苏 139 & $\mathrm{P}_{1} s, \mathrm{P}_{2} x$ & 93.16 & 3.05 & 0.51 & 0.07 & 0.07 & 96.86 & 1.31 & 1.45 & -30.4 & -24.2 & -26.8 & -23.7 & -192 & -178 & -180 \\
\hline & & 7 & 苏 336 & $\mathrm{P}_{1} s, \mathrm{P}_{2} x$ & 90.20 & 1.40 & 0.15 & 0.02 & 0.01 & 91.78 & 0.00 & 8.06 & -28.7 & -22.6 & -25.1 & & -189 & -169 & -168 \\
\hline & & 8 & 苏 14-0-31 & $\mathrm{P}_{1} s, \mathrm{P}_{2} x$ & 93.00 & 4.05 & 0.65 & 0.11 & 0.10 & 97.91 & 1.20 & 0.59 & -32.0 & -23.8 & -24.7 & -22.0 & -196 & -168 & -172 \\
\hline & & 9 & 苏 48-2-86 & $\mathrm{P}_{1} s$ & 92.85 & 4.00 & 0.63 & 0.11 & 0.10 & 97.69 & 1.44 & 0.57 & -31.7 & -23.2 & -24.3 & -22.3 & -190 & -172 & -170 \\
\hline & & 10 & 苏 48-14-76 & $\mathrm{P}_{1} s, \mathrm{P}_{2} x$ & 92.73 & 3.48 & 0.65 & 0.13 & 0.11 & 97.10 & 1.47 & 1.14 & -33.5 & -22.8 & -24.2 & -22.2 & -192 & -172 & -171 \\
\hline & & 11 & 苏 48-15-68 & $\mathrm{P}_{2} x_{8}$ & 92.79 & 3.28 & 0.61 & 0.11 & 0.12 & 96.91 & 1.70 & 1.07 & -29.8 & -23.4 & -25.0 & -22.6 & -195 & -170 & -172 \\
\hline & & 12 & 苏 53-78-46H & $\mathrm{P}_{1} s, \mathrm{P}_{2} x$ & 89.82 & 6.21 & 1.24 & 0.22 & 0.24 & 97.73 & 0.93 & 0.87 & -33.9 & -23.9 & -23.0 & -23.2 & -198 & -165 & -156 \\
\hline & & 13 & 苏 75-64-5X & $\mathrm{P}_{2} x$ & 89.45 & 6.36 & 1.26 & 0.22 & 0.24 & 97.53 & 0.13 & 0.93 & -33.5 & -24.0 & -23.3 & -22.8 & -199 & -167 & -159 \\
\hline & & 14 & 苏 76-1-4 & $\mathrm{P}_{2} x$ & 90.38 & 6.03 & 1.18 & 0.21 & 0.22 & 98.02 & 0.82 & 0.71 & -32.7 & -23.6 & -22.9 & -23.0 & -198 & -168 & -165 \\
\hline & & 15 & 苏 77-2-5 & $\mathrm{P}_{2} x$ & 89.90 & 5.53 & 1.24 & 0.24 & 0.27 & 97.18 & 1.46 & 0.70 & -30.8 & -22.7 & -23.3 & -22.9 & -194 & -168 & -164 \\
\hline & & 16 & 苏 77-6-8 & $\mathrm{P}_{2} x^{8}$ & 89.90 & 5.80 & 1.24 & 0.22 & 0.24 & 97.40 & 0.60 & 0.79 & -33.6 & -23.9 & -24.1 & -23.5 & -201 & -165 & -165 \\
\hline & & 17 & 苏 $120-52-82$ & $\mathrm{P}_{1} s, \mathrm{P}_{2} x$ & 91.64 & 3.69 & 0.64 & 0.11 & 0.10 & 96.18 & 2.58 & 0.93 & -31.1 & -23.3 & -25.6 & -23.6 & -192 & -176 & -179 \\
\hline & & 18 & 召 61 & $\mathrm{P}_{1} s$ & 88.98 & 6.83 & 1.53 & 0.31 & 0.37 & 98.02 & 0.55 & 0.85 & -33.2 & -23.5 & -23.3 & -23.2 & -194 & -159 & -154 \\
\hline & \multirow{2}{*}{ 榆林 } & 19 & 榆 217 & $\mathrm{P}_{1} s$ & 93.02 & 2.69 & 0.36 & 0.05 & 0.05 & 96.17 & 1.84 & 0.32 & -31.1 & -26.5 & -24.4 & -23.4 & -201 & -183 & -171 \\
\hline & & 20 & 榆 43-6 & $\mathrm{P}_{1} s$ & 88.81 & 6.04 & 2.03 & 0.50 & 0.57 & 97.95 & 0.24 & n.d & -31.6 & -26.1 & -23.8 & -22.9 & -201 & -181 & -172 \\
\hline & \multirow{3}{*}{ 子洲 } & 21 & 洲 1 & $\mathrm{O}_{1}$ & 94.43 & 2.64 & 0.35 & 0.05 & 0.05 & 97.51 & 1.17 & 1.09 & -34.9 & -23.8 & -21.8 & -21.0 & -191 & -174 & -149 \\
\hline & & 22 & 洲 16-19 & $\mathrm{P}_{1} s$ & 91.53 & 5.22 & 1.16 & 0.19 & 0.20 & 98.30 & 0.06 & n.d. & -34.5 & -24.3 & -21.7 & -21.7 & -199 & -169 & -164 \\
\hline & & 23 & 洲 22-18 & $\mathrm{P}_{1} s$ & 93.12 & 4.22 & 0.76 & 0.14 & 0.13 & 98.37 & 0.02 & n.d. & -31.1 & -25.7 & -24.3 & -23.1 & -198 & -174 & -175 \\
\hline & \multirow{8}{*}{ 大牛地 } & 24 & D11 & $\mathrm{P}_{2} s h^{1}$ & 94.66 & 2.90 & 0.53 & 0.08 & 0.11 & 98.28 & 0.18 & 1.39 & -34.5 & -26.3 & -24.7 & -22.9 & -192 & -166 & -165 \\
\hline & & 25 & D13 & $\mathrm{P}_{1} s$ & 94.49 & 1.71 & 0.31 & \multicolumn{2}{|c|}{0.07} & 96.58 & 0.28 & 0.25 & -36.0 & -25.7 & -24.5 & -22.6 & -206 & -164 & -156 \\
\hline & & 26 & D16 & $\mathrm{P}_{2} s h$ & 94.37 & 2.52 & 0.26 & 0.06 & 0.09 & 97.31 & 0.37 & 1.96 & -35.1 & -27.1 & -26.0 & -23.9 & -192 & -167 & -164 \\
\hline & & 27 & D22 & $\mathrm{P}_{1} t^{2}$ & 86.21 & 4.11 & 0.81 & 0.11 & 0.13 & 91.37 & 1.05 & 7.31 & -38.1 & -25.3 & -23.0 & -21.7 & -204 & -160 & -159 \\
\hline & & 28 & D24 & $\mathrm{P}_{2} s h^{1}$ & 87.95 & 6.92 & 1.83 & 0.45 & 0.63 & 97.78 & 0.33 & 1.49 & -37.1 & -26.1 & -25.3 & -23.7 & -210 & -170 & -172 \\
\hline & & 29 & DK4 & $\mathrm{P}_{2} s h^{3}$ & 96.19 & 2.48 & 0.32 & 0.05 & 0.05 & 99.09 & 0.32 & 0.35 & -34.9 & -26.4 & -24.0 & -23.0 & -187 & -164 & -154 \\
\hline & & 30 & DK9 & $\mathrm{P}_{2} s h^{1}$ & 96.31 & 2.21 & 0.18 & 0.04 & 0.03 & 98.77 & 0.26 & 0.42 & -35.0 & -26.0 & -23.4 & -21.9 & -185 & -164 & -160 \\
\hline & & 31 & DK17 & $\mathrm{P}_{2} s$ & 93.64 & 3.46 & 0.54 & 0.08 & 0.11 & 97.83 & 0.18 & 1.64 & -36.0 & -27.2 & -25.6 & -23.3 & -186 & -164 & -156 \\
\hline & & 32 & 米 $37-13$ & $\mathrm{P}_{1} s$ & 94.19 & 3.77 & 0.53 & 0.11 & 0.09 & 98.69 & 0.71 & 0.39 & -33.0 & -23.2 & -22.4 & -21.1 & -182 & -156 & -145 \\
\hline & & 33 & 榆 12 & $\mathrm{P}_{2} s h$ & 91.24 & 5.81 & 0.84 & 0.17 & 0.16 & 98.22 & 1.13 & 0.04 & -34.2 & -26.3 & -24.0 & -23.2 & n.d. & n.d. & n.d. \\
\hline & & 34 & 乌 $22-7$ & $\mathrm{P}_{2} x$ & 92.97 & 4.27 & 0.76 & 0.11 & 0.11 & 98.22 & 0.74 & 0.87 & -32.2 & -23.5 & -24.9 & -21.9 & n.d. & n.d. & n.d. \\
\hline & 乌审旗 & 35 & 陕 215 & $\mathrm{P}_{2} s h$ & 93.60 & 3.79 & 0.55 & 0.08 & 0.08 & 98.10 & 0.76 & 0.46 & -32.9 & -26.0 & -24.0 & -22.3 & n.d. & n.d. & n.d. \\
\hline & & 36 & 陕 243 & $\mathrm{P}_{2} x$ & 90.85 & 5.46 & 1.03 & 0.18 & 0.17 & 97.69 & 0.54 & 1.55 & -35.0 & -24.0 & -23.6 & -22.4 & n.d. & n.d. & n.d. \\
\hline & & 37 & 神 1 & $\mathrm{P}_{2} x$ & 92.86 & 4.69 & 1.23 & 0.16 & 0.18 & 99.12 & n.d. & 0.73 & -37.1 & -24.7 & -24.5 & -23.9 & n.d. & n.d. & n.d. \\
\hline & 神木 & 38 & 双 15 & $\mathrm{P}_{1} s$ & 93.65 & 3.59 & 0.75 & 0.16 & 0.13 & 98.28 & 1.45 & 0.42 & -35.9 & -23.6 & -22.6 & -22.2 & n.d. & n.d. & n.d. \\
\hline & & 39 & 双 20 & $\mathrm{P}_{1} t$ & 93.06 & 3.22 & 0.56 & 0.11 & 0.10 & 97.05 & 2.47 & 0.82 & -35.8 & -25.6 & -24.0 & -23.0 & n.d. & n.d. & n.d. \\
\hline & & 40 & 合川 106 & $\mathrm{~T}_{3} x^{2}$ & 89.28 & 6.83 & 1.87 & 0.46 & 0.37 & 98.81 & 0.21 & 0.39 & -39.8 & -27.0 & -24.1 & n.d. & -172 & -129 & -119 \\
\hline & & 41 & 合川 108 & $\mathrm{~T}_{3} x^{2}$ & 85.76 & 8.24 & 3.25 & 0.67 & 0.68 & 98.60 & 0.26 & 0.54 & -41.4 & -28.3 & -25.0 & -27.2 & -183 & -135 & -118 \\
\hline & & 42 & 合川 109 & $\mathrm{~T}_{3} x^{2}$ & 92.54 & 5.15 & 0.98 & 0.28 & 0.20 & 99.15 & 0.15 & 0.31 & -38.3 & -26.2 & -23.6 & n.d. & -163 & -136 & -126 \\
\hline & & 43 & 合川 001-1 & $\mathrm{T}_{3} x^{2}$ & 89.27 & 6.98 & 1.89 & 0.46 & 0.35 & 98.95 & 0.16 & 0.44 & -39.5 & -27.1 & -23.9 & -24.4 & -169 & -132 & -116 \\
\hline 四川 & 合川 & 44 & 合川 001-2 & $\mathrm{T}_{3} x^{2}$ & 89.87 & 6.64 & 1.69 & 0.43 & 0.32 & 98.95 & 0.16 & 0.41 & -39.0 & -26.8 & -23.8 & n.d. & -166 & -120 & -111 \\
\hline & & 45 & $\begin{array}{c}\text { 合川 } \\
001-30-x\end{array}$ & $\mathrm{~T}_{3} x^{2}$ & 90.46 & 6.14 & 1.51 & 0.41 & 0.35 & 98.87 & 0.20 & 0.39 & -38.8 & -27.6 & -24.5 & -25.5 & -166 & -121 & -120 \\
\hline & & 46 & 潼南 104 & $\mathrm{~T}_{3} x^{2}$ & 86.44 & 7.69 & 2.96 & 0.73 & 0.67 & 98.49 & 0.26 & 0.43 & -41.0 & -27.4 & -24.0 & -26.7 & -179 & -128 & -119 \\
\hline & & 47 & 潼南 105 & $\mathrm{~T}_{3} x^{2}$ & 87.78 & 7.42 & 2.32 & 0.57 & 0.50 & 98.59 & 0.27 & 0.37 & -40.4 & -27.4 & -24.0 & -25.9 & -173 & -128 & -118 \\
\hline & & 48 & 潼南 001-2 & $\mathrm{T}_{3} x^{2}$ & 87.10 & 7.65 & 2.56 & 0.65 & 0.59 & 98.55 & 0.30 & 0.39 & -40.7 & -27.5 & -24.5 & -26.1 & -176 & -123 & -116 \\
\hline
\end{tabular}


中国科学：地球科学 2014 年 第 44 卷 第 4 期

续表 2

\begin{tabular}{|c|c|c|c|c|c|c|c|c|c|c|c|c|c|c|c|c|c|c|c|}
\hline \multirow{2}{*}{ 盆地 } & \multirow{2}{*}{ 气田 } & \multirow{2}{*}{ 序号 } & \multirow{2}{*}{ 井 } & \multirow{2}{*}{ 地层 } & \multicolumn{8}{|c|}{ 组分(vol\%) } & \multicolumn{4}{|c|}{$\delta^{13} \mathrm{C}(\%, \mathrm{VPDB})$} & \multicolumn{3}{|c|}{$\delta^{2} \mathrm{H}(\% o$, VSMOW $)$} \\
\hline & & & & & $\mathrm{CH}_{4}$ & $\mathrm{C}_{2} \mathrm{H}_{6}$ & $\mathrm{C}_{3} \mathrm{H}_{8}$ & $\mathrm{iC}_{4}$ & $\mathrm{nC}_{4}$ & $\mathrm{C}_{1 \sim 4}$ & $\mathrm{CO}_{2}$ & $\mathrm{~N}_{2}$ & $\delta \mathrm{C}_{1}$ & $\delta \mathrm{C}_{2}$ & $\delta \mathrm{C}_{3}$ & $\delta \mathrm{C}_{4}$ & $\delta^{2} \mathrm{H}_{1}$ & $\delta^{2} \mathrm{H}_{2}$ & $\delta^{2} \mathrm{H}_{3}$ \\
\hline \multirow{29}{*}{ 四川 } & \multirow{5}{*}{ 新场 } & 49 & 川孝 254 & $\mathrm{~J}_{3} p$ & 93.16 & 4.47 & 1.09 & 0.22 & 0.23 & 99.17 & 0.00 & 0.68 & -33.2 & -24.0 & -21.6 & -21.3 & -176 & -151 & -147 \\
\hline & & 50 & 川孝 263 & $\mathbf{J}_{2} s$ & 91.95 & 5.20 & 1.46 & 0.26 & 0.35 & 99.22 & 0.00 & 0.36 & -33.4 & -24.8 & -22.3 & -21.7 & -178 & -143 & -137 \\
\hline & & 51 & 川孝 480-1 & $\mathbf{J}_{2} s$ & 91.65 & 5.70 & 1.34 & 0.27 & 0.30 & 99.26 & 0.00 & 0.32 & -34.8 & -23.7 & -20.1 & -20.0 & -182 & -147 & -117 \\
\hline & & 52 & 川孝 480-2 & $\mathrm{J}$ & 92.62 & 4.94 & 1.23 & 0.26 & 0.26 & 99.31 & 0.00 & 0.32 & -34.6 & -24.4 & -22.1 & -21.5 & -178 & -147 & -147 \\
\hline & & 53 & 新 882 & $\mathrm{~T}_{3} x^{4}$ & 93.41 & 3.78 & 0.93 & 0.20 & 0.18 & 98.50 & 0.46 & 0.85 & -34.3 & -23.1 & -21.4 & -20.0 & -182 & -151 & -147 \\
\hline & \multirow{2}{*}{ 广安 } & 54 & 广安 56 & $\mathrm{~T}_{3} x^{6}$ & 88.98 & 6.16 & 2.51 & 0.57 & 0.60 & 98.82 & 0.29 & 0.40 & -39.2 & -27.4 & -26.0 & -24.2 & n.d. & n.d. & n.d. \\
\hline & & 55 & 广安 002-39 & $\mathrm{T}_{3} x^{6}$ & 94.28 & 4.36 & 0.50 & 0.18 & 0.08 & n.d. & 0.10 & 0.50 & -38.8 & -26.9 & -25.6 & -24.7 & -180 & -145 & -146 \\
\hline & \multirow{5}{*}{ 安岳 } & 56 & 岳 101 & $\mathrm{~T}_{3} x^{2}$ & 84.38 & 7.87 & 2.50 & 0.69 & 0.79 & 96.23 & 0.35 & 0.71 & -41.3 & -26.8 & -23.7 & -25.2 & -188 & -132 & -125 \\
\hline & & 57 & 岳 105 & $\mathrm{~T}_{3} x^{2}$ & 84.64 & 8.67 & 3.86 & 0.70 & 0.73 & 98.60 & 0.29 & 0.59 & -41.6 & -28.5 & -25.4 & -26.2 & -183 & -129 & -119 \\
\hline & & 58 & 岳 101-11 & $\mathrm{T}_{3} x^{2}$ & 83.95 & 10.13 & 3.50 & 0.70 & 0.60 & 98.88 & 0.30 & 0.43 & -41.1 & -26.3 & -23.0 & -25.1 & -178 & -129 & -117 \\
\hline & & 59 & 岳 101-X12 & $\mathrm{T}_{3} x^{2}$ & 84.18 & 9.97 & 2.83 & 0.66 & 0.59 & 98.23 & 0.00 & 0.51 & -40.8 & -27.5 & -23.8 & -25.3 & -184 & -129 & -120 \\
\hline & & 60 & 岳 $101-X 12$ & $\mathrm{~T}_{3} x^{2}$ & 83.86 & 10.13 & 2.89 & 0.68 & 0.62 & 98.18 & 0.00 & 0.47 & -40.8 & -27.3 & -23.3 & -24.7 & -181 & -131 & -116 \\
\hline & \multirow{4}{*}{ 八角场 } & 61 & 角 33 & $\mathrm{~T}_{3} x^{4}$ & 92.95 & 4.93 & 1.14 & 0.20 & 0.24 & 99.46 & n.d. & 0.38 & -40.1 & -27.4 & -24.6 & -24.6 & -182 & -144 & -138 \\
\hline & & 62 & 角 48 & $\mathrm{~T}_{3} x^{6}$ & 91.90 & 5.30 & 1.38 & 0.26 & 0.31 & 99.15 & n.d. & 0.67 & -40.3 & -26.5 & -24.2 & -22.7 & -185 & -153 & -142 \\
\hline & & 63 & 角 49 & $\mathrm{~T}_{3} x^{2}$ & 96.26 & 2.85 & 0.53 & 0.10 & 0.09 & 99.83 & n.d. & 0.11 & -37.0 & -27.3 & -24.2 & -22.9 & -172 & -144 & -139 \\
\hline & & 64 & 角 57 & $\mathrm{~T}_{3} x$ & 90.99 & 5.51 & 1.71 & 0.33 & 0.33 & 98.87 & 0.41 & 0.25 & -37.3 & -25.5 & -22.9 & -22.7 & -178 & -144 & -138 \\
\hline & \multirow{5}{*}{ 洛带 } & 65 & 龙 3 & $\mathrm{~J}_{3} p$ & 86.41 & 5.00 & 1.76 & 0.39 & 0.51 & 94.07 & 0.00 & 5.33 & -34.0 & -23.0 & -21.0 & -20.6 & -173 & -143 & -143 \\
\hline & & 66 & 龙 42 & $\mathrm{~J}_{3} p$ & 90.52 & 4.96 & 1.50 & 0.32 & 0.39 & 97.69 & n.d. & 1.80 & -32.9 & -24.0 & -21.2 & -21.3 & -173 & -144 & -143 \\
\hline & & 67 & 龙 55 & $\mathrm{~J}_{3} p$ & 90.01 & 5.45 & 1.76 & 0.40 & 0.48 & 98.10 & 0.00 & 1.19 & -34.4 & -24.6 & -21.9 & -21.6 & -176 & -144 & -131 \\
\hline & & 68 & LS 3 & $\mathrm{~J}_{3} s n$ & 89.65 & 5.87 & 1.90 & 0.41 & 0.50 & 98.33 & 0.00 & 0.96 & -33.7 & -24.3 & -21.4 & -21.0 & -180 & -146 & -126 \\
\hline & & 69 & LS 35 & $\mathrm{~J}_{3} s n$ & 88.72 & 6.00 & 2.03 & 0.41 & 0.52 & 97.68 & n.d. & 1.70 & -33.5 & -24.0 & -21.5 & -21.2 & -177 & -145 & -117 \\
\hline & \multirow{8}{*}{ 邛西 } & 70 & 邛西 3 & $\mathrm{~T}_{3} x^{2}$ & 93.57 & 3.85 & 0.59 & 0.09 & 0.07 & 98.17 & 1.55 & 0.23 & -33.1 & -23.0 & -22.7 & -20.6 & -173 & -145 & -150 \\
\hline & & 71 & 邛西 4 & $\mathrm{~T}_{3} x^{2}$ & 93.52 & 3.19 & 0.62 & 0.10 & 0.08 & 97.51 & 1.47 & 0.24 & -32.9 & -23.2 & -23.0 & -22.0 & -173 & -145 & -152 \\
\hline & & 72 & 邛西 6 & $\mathrm{~T}_{3} x^{2}$ & 95.95 & 2.48 & 0.30 & 0.04 & 0.04 & 98.81 & 0.92 & 0.21 & -31.2 & -23.2 & -23.1 & -20.9 & -174 & -144 & -133 \\
\hline & & 73 & 邛西 10 & $\mathrm{~T}_{3} x^{2}$ & 93.57 & 3.85 & 0.59 & 0.09 & 0.07 & 98.17 & 1.55 & 0.23 & -33.2 & -22.8 & -22.8 & -20.4 & -170 & -147 & -138 \\
\hline & & 74 & 邛西 13 & $\mathrm{~T}_{3} x^{2}$ & 93.49 & 3.90 & 0.63 & 0.11 & 0.08 & 98.21 & 1.47 & 0.25 & -33.7 & -24.1 & -23.4 & -20.9 & -174 & -146 & -152 \\
\hline & & 75 & 邛西 14 & $\mathrm{~T}_{3} x^{2}$ & 96.50 & 1.57 & 0.12 & 0.02 & 0.01 & 98.22 & 1.55 & 0.23 & -30.5 & -24.1 & -23.8 & n.d. & -173 & -147 & -152 \\
\hline & & 76 & 邛西 16 & $\mathrm{~T}_{3} x^{2}$ & 96.46 & 1.74 & 0.16 & 0.02 & 0.02 & 98.40 & 1.39 & 0.20 & -30.8 & -23.8 & n.d. & n.d. & -175 & -146 & -154 \\
\hline & & 77 & 邛西 006-X1 & $\mathrm{T}_{3} x^{2}$ & 93.17 & 4.12 & 0.71 & 0.13 & 0.11 & 98.24 & 1.36 & 0.26 & -31.6 & -22.4 & -22.4 & n.d. & -173 & -144 & -154 \\
\hline \multirow{4}{*}{ 塔里木 } & \multirow{4}{*}{ 大北 } & 78 & 大北 102 & $\mathrm{~K}$ & 96.01 & 2.08 & 0.38 & 0.09 & 0.09 & 98.65 & 0.44 & 0.64 & -29.5 & -21.6 & -21.0 & -22.5 & -168 & -135 & -129 \\
\hline & & 79 & 大北 103 & K & 95.67 & 2.21 & 0.43 & 0.10 & 0.11 & 98.52 & 0.53 & 0.66 & -30.2 & -22.3 & -21.1 & -22.3 & -171 & -132 & -117 \\
\hline & & 80 & 大北 201 & K & 96.04 & 1.93 & 0.35 & 0.08 & 0.09 & 98.49 & 0.53 & 0.65 & -28.9 & -21.7 & -20.9 & -22.3 & -168 & -128 & -111 \\
\hline & & 81 & 大北 202 & K & 96.56 & 1.57 & 0.27 & 0.06 & 0.07 & 98.53 & 0.54 & 0.64 & -28.6 & -20.5 & -20.6 & -22.2 & -168 & -126 & -110 \\
\hline
\end{tabular}

\section{1 中国致密砂岩大气田烷烃气碳同位素组成具 有煤成气的特征}

戴金星(1992)综合了中国各盆地、德国西北盆 地、库珀盆地、瓦尔沃得-德拉瓦尔盆地、北海盆地、 安大略盆地以及前苏联 11 个油气田大量油型气和煤 成气的 $\delta^{13} \mathrm{C}_{1}, \delta^{13} \mathrm{C}_{2}$ 和 $\delta^{13} \mathrm{C}_{3}$ 值, 戴金星等(2014)予以 完善而编制了 $\delta^{13} \mathrm{C}_{1}-\delta^{13} \mathrm{C}_{2}-\delta^{13} \mathrm{C}_{3}$ 图版鉴别煤成气和油 型气. 把表 2 中所有 $\delta^{13} \mathrm{C}_{1}, \delta^{13} \mathrm{C}_{2}$ 和 $\delta^{13} \mathrm{C}_{3}$ 值投入该图 版中(图 2), 可见中国致密砂岩大气田的天然气均属 于来自含煤岩系的煤成气.

Whiticar(1999)根据 $\delta^{13} \mathrm{C}_{1}-\mathrm{C}_{1} / \mathrm{C}_{2+3}$ 参数编制了天 然气成因鉴别图版(图 3), 把表 2 中各井 $\delta^{13} \mathrm{C}_{1}$ 值与
$\mathrm{C}_{1} / \mathrm{C}_{2+3}$ 投入该图版(图 3), 表明中国致密砂岩大气田 的天然气是由III型干酪根的源岩生成的煤成气。

中国致密砂岩气田烷烃气 $\delta^{13} \mathrm{C}_{1}-\delta^{13} \mathrm{C}_{2}$ 回归线和 Sacramento 盆地(Jenden 等, 1988)以及尼日尔三角洲 (Rooney 等, 1995)III 型源岩生成的煤成气具有相似性, 说明中国致密砂岩气属于煤成气(图 4).

不仅天然气的 $\delta^{13} \mathrm{C}_{1}-\delta^{13} \mathrm{C}_{2}-\delta^{13} \mathrm{C}_{3}$ 图版, $\delta^{13} \mathrm{C}_{1}-\mathrm{C}_{1} /$ $\mathrm{C}_{2+3}$ 图版以及 $\delta^{13} \mathrm{C}_{1}-\delta^{13} \mathrm{C}_{2}$ 回归线都可确定中国致密砂 岩大气田的天然气是来自含煤岩系的煤成气，同时 通过对中国各盆地致密砂岩大气田的生储盖组合, TOC 值和成藏等特征的分析也支持致密砂岩大气田 的气源是煤成气. 由图 5 可知, 鄂尔多斯盆地山西组、 


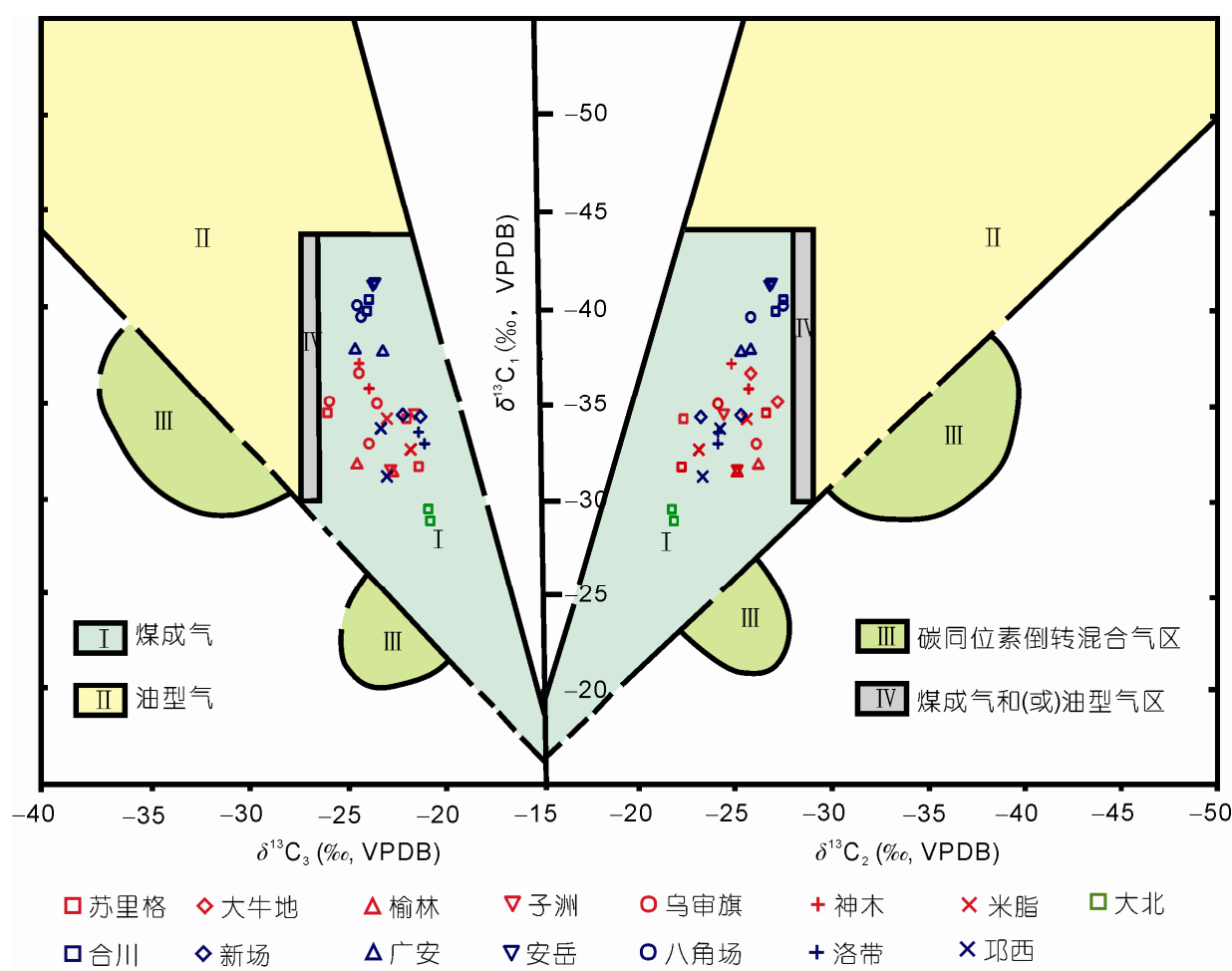

图 $2 \delta^{13} \mathrm{C}_{1}-\delta^{13} \mathrm{C}_{2}-\delta^{13} \mathrm{C}_{3}$ 有机不同成因烷烃气鉴别图版 据戴金星(1992)和戴金星等(2014)编绘

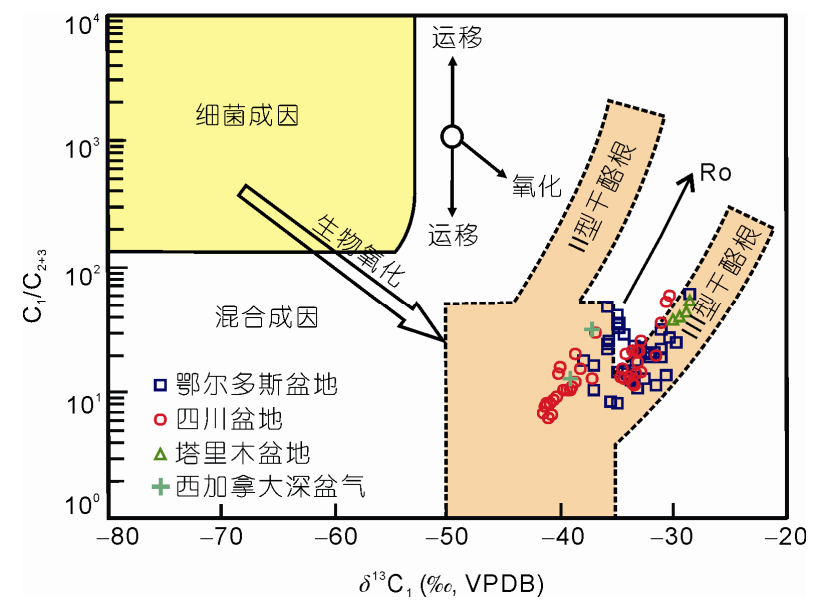

图 $3 \delta^{13} \mathbf{C}_{1}-\mathbf{C}_{1} / \mathbf{C}_{2+3}$ 天然气成因鉴别图版 据 Whiticar (1999)

太原组和本溪组是中国华北地区著名的大面积稳定 展布的煤系，一般煤层总厚度为 10 15 m, 局部大于 $40 \mathrm{~m}$, 煤及泥岩累计厚度可达 $200 \mathrm{~m}$ 左右(Dai 等, 2005a); 煤的平均有机碳含量为 $60 \%$, 暗色泥质岩有 机碳含量在 $1 \% \sim 5 \%$, 高的可达 $10 \%$ 以上, 一般为 $2 \% \sim 4 \%$, 以III型干酪根为主, 是一套好的气源岩(戴
金星，1980；张士亚，1994；杨俊杰和裴锡古，1996; Dai 等, 2005a); 本溪组、太原组和山西组是海陆交互 相, 分别产有 2 5 $\mathrm{m}$ 和 20 40 $\mathrm{m}$ 的石灰岩, TOC 含量 一般分布在 $0.5 \%$ 5\%, 以 II ${ }_{1}$ 型干酪根为主，石炭岩 最厚发育在靖边气田地区, 向外减薄或缺失, 在苏里 格气田地区厚度常在 $10 \mathrm{~m}$ 以下, 是一套分布区域有

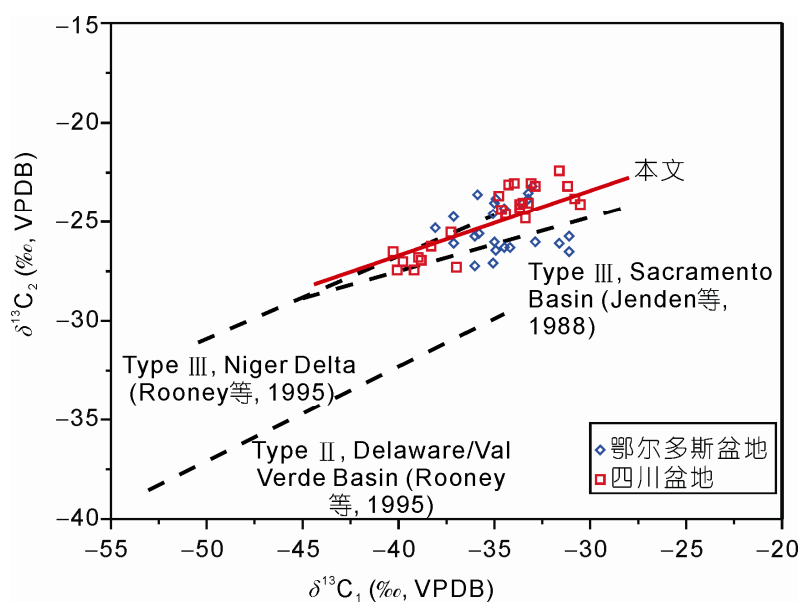

图 $4 \delta^{13} C_{1}-\delta^{13} C_{2}$ 回归线对比 
限的次要油型气源岩, 仅在靖边气田发现部分油型 气或煤成气和油型气的混合气(Dai 等, 2005a). 该煤 系下伏地层是经过 1.4 亿年古喀斯特作用形成的下奥 陶统马家沟组泥质云岩偶夹石膏层. 根据马家沟组 泥质云岩 449 个样品的 TOC 分析, TOC 最高值为 $1.81 \%$, 最低值为 $0.04 \%$, 平均值为 $0.24 \%$ (夏新宇, 2000; Dai 等, 2005a). 因此, 马家沟组为非烃源岩, 故该套煤系中以及煤系之上的紫色, 红色或杂色的 下石盒子组 $\left(\mathrm{P}_{2} x\right)$, 上石盒子组 $\left(\mathrm{P}_{2} s h\right)$ 和石千峰组 $\left(\mathrm{P}_{3} s\right)$ 中气层, 其气源岩只能是本溪组, 太原组和山西组煤
系. 从图 5 可看出, 从本溪组到石千峰组各相关 $\delta^{13} \mathrm{C}$ 值, 特别是 $\delta^{13} \mathrm{C}_{2}, \delta^{13} \mathrm{C}_{3}$ 和 $\delta^{13} \mathrm{C}_{4}$ 值具有上下基本一致 性, 旁证了石千峰组, 上石盒子组和下石盒子组气源 来自下伏煤系烃源岩.

图 6 为四川盆地致密砂岩大气田的主要产气层 须家河组须 2 段 $\left(\mathrm{T}_{3} x^{2}\right)$, 须 4 段 $\left(\mathrm{T}_{3} x^{4}\right)$ 和须 6 段 $\left(\mathrm{T}_{3} x^{6}\right)$, 与次要产层上沙溪庙组 $\left(\mathrm{J}_{2} s\right)$, 遂宁组 $\left(\mathrm{J}_{2} s n\right)$ 和蓬莱镇 组 $\left(\mathrm{J}_{3} p\right)$ 的地层柱状图及 TOC, 碳氢同位素值的垂直 剖面分布图. 须家河组煤系底一般与中三叠统雷口 坡组海相的灰白色白云岩或部分灰岩接触，该组碳

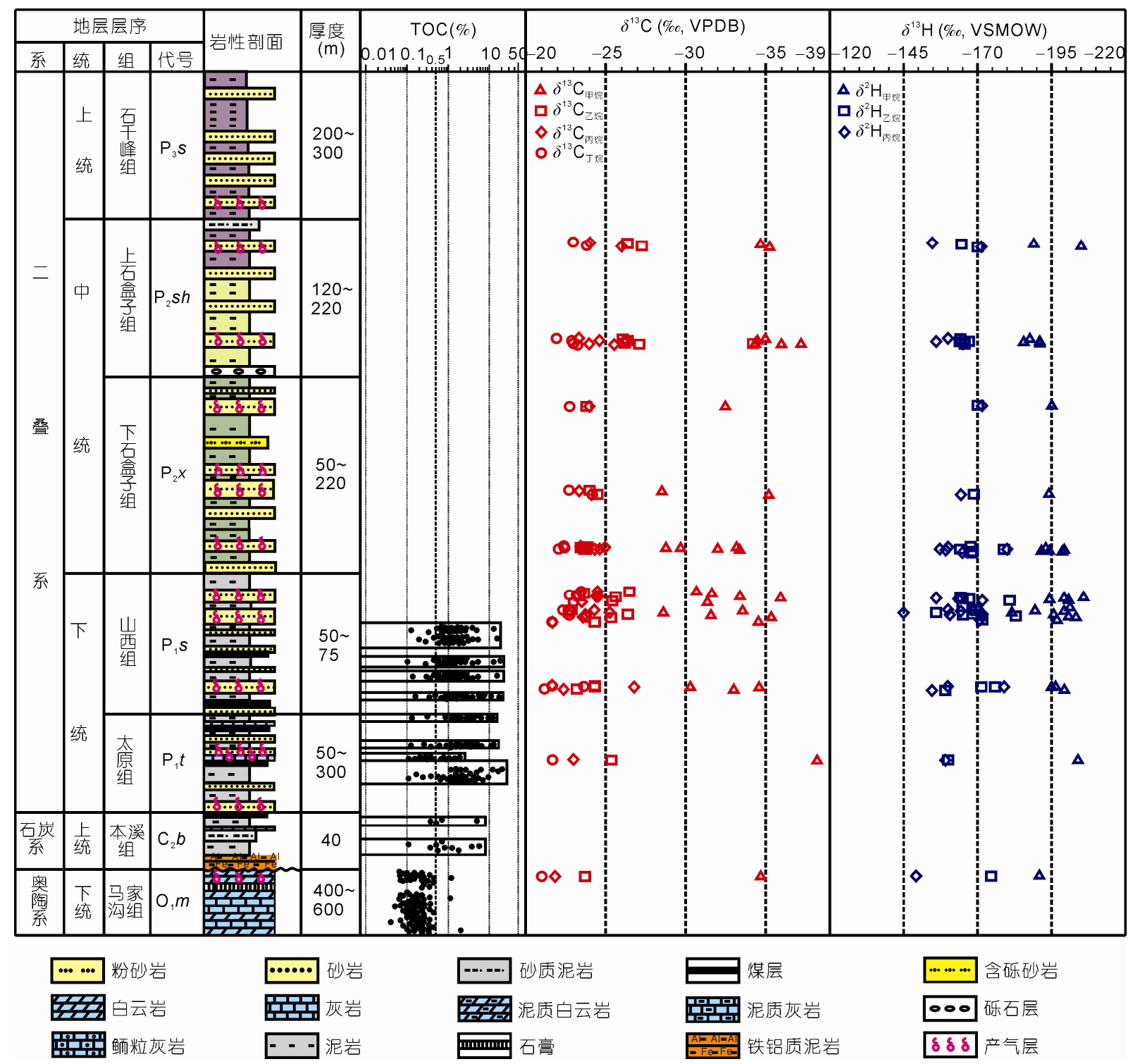

图 5 鄂尔多斯盆地上古生界致密砂岩大气田产层综合地层及 $\delta^{13} \mathrm{C}_{1 \sim 4}$ 和 $\delta^{2} \mathrm{H}_{1 \sim 3}$ 值图 


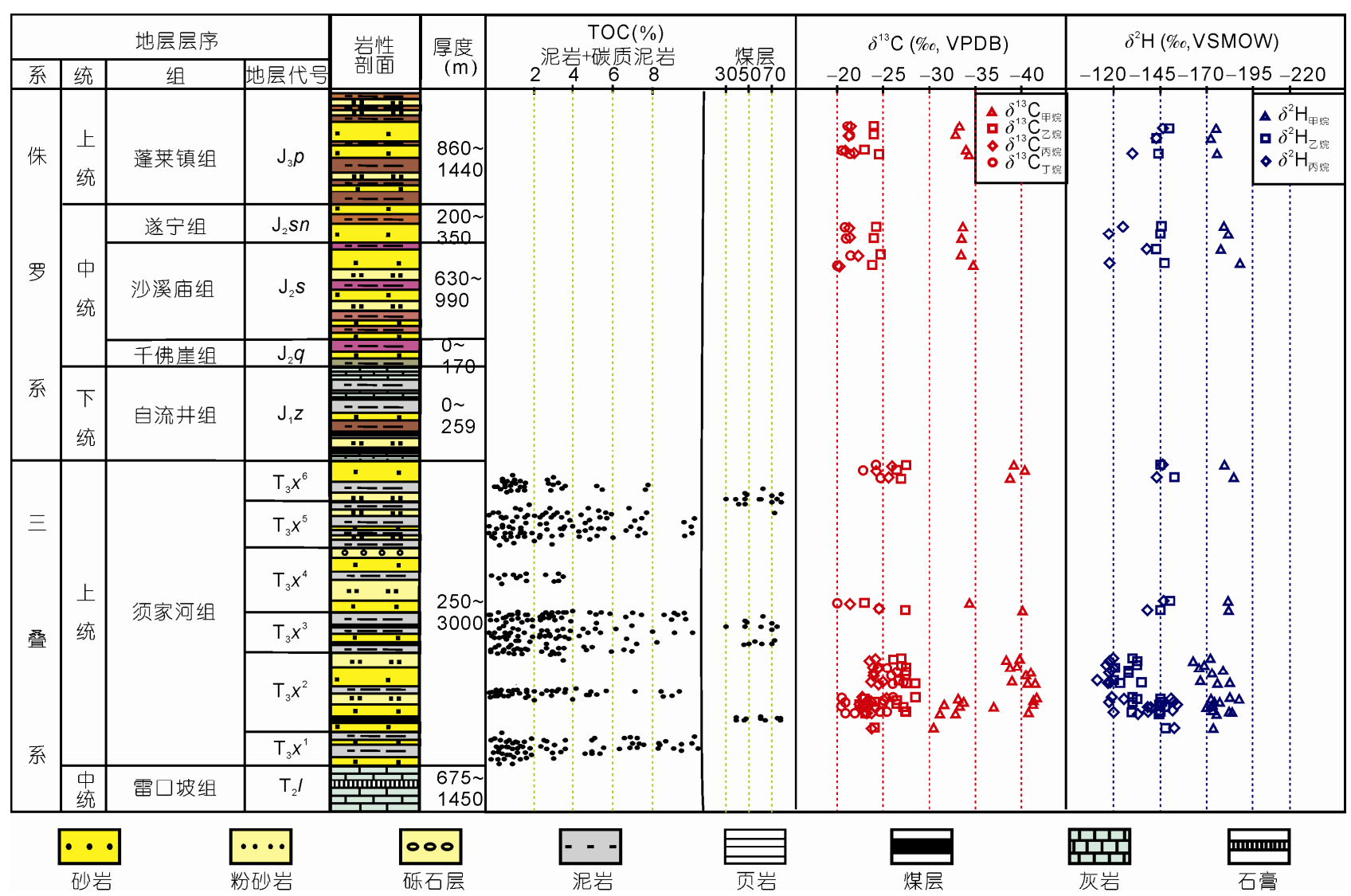

图 6 四川盆地中生界中部致密砂岩大气田的产层综合地层及 $\delta^{13} \mathrm{C}_{1 \sim 4}$ 和 $\delta^{2} \mathrm{H}_{1 \sim 3}$ 值图

酸盐岩 60 个样品平均 TOC 为 $0.13 \%$ (翟光明, 1989), 为非烃源岩. 陆相为主的须家河组分六段, 一、三、 五段为以平原沼泽相沉积为主的深灰色, 灰色泥岩, 页岩夹煤层，间夹少许石英砂岩和粉砂岩，是烃源岩， 烃源岩西厚东薄, 暗色泥岩厚 $10 \sim 1500 \mathrm{~m}$, 平均厚 $232 \mathrm{~m}$. 煤系烃源岩有机质丰度较高, 据对 863 块样 品分析统计, 泥岩有机碳含量为 $0.5 \%$ 6.5\%, 绝大部 分样品大于 $1.0 \%$, 烃源岩有机显微组分是镜质组-㤢 质组组合, 壳质组和腐泥组含量低, 属腐殖型. 盆地 西部烃源岩 $R_{\mathrm{o}}$ 普遍大于 $1.5 \%$, 而在盆地中部一般小 于 $1.3 \%$ (戴金星等, 2000). 须二、四、六段为以分支 河道和河口坝(须六段) 沉积为主的灰色, 深灰色石 英砂岩, 岩屑砂岩夹深灰色砂质页岩, 页岩, 薄煤层 或煤线, 是储层. 沙溪庙组, 遂宁组和蓬莱镇组是棕 紫色, 紫红色, 棕红色泥岩, 砂质泥岩与岩屑砂岩, 含钻砂岩不等厚互层. 从泥质岩颜色可知这三组为 非烃源岩而可作储层. 此三组产气层以下自流井组 有暗色泥岩和介壳灰岩, 干酪根为 $\mathrm{II}_{1}$ 型为主, 处于
生油阶段, 目前产少量含伴生气极低的石油, 由图 6 纵向气层 $\delta^{13} \mathrm{C}_{1 \sim 4}$ 值一致性, 说明油型气未对其上产 气层产生影响。

由图 6 可知, 从须二段 $\left(\mathrm{T}_{3} x^{2}\right)$ 至蓬莱镇组 $\left(\mathrm{J}_{3} p\right)$ 各 相关 $\delta^{13} \mathrm{C}$ 值 特别是 $\delta^{13} \mathrm{C}_{2}, \delta^{13} \mathrm{C}_{3}$ 和 $\delta^{13} \mathrm{C}_{4}$ 值具有上下 基本一致性, 旁证了蓬莱镇组, 遂宁组和上沙溪庙组 这些杂色地层中天然气气源是从下伏须家河组煤系 烃源岩中运移来的, 而运移未使同位素产生明显分 馏, 这情况与图 5 中 $\delta^{13} \mathrm{C}$ 十分相似.

为什么中国致密砂岩大气田的天然气均为来自 含煤岩系的煤成气? 这是因为致密砂岩孔渗很低, 由于腐殖煤系是 “全天候”气源岩, 从褐煤开始至无 烟煤各煤阶的成烃作用中都以形成天然气为主，而 且含煤岩系分布广而稳定, 能有长期供应的充足气 源, 致使致密砂岩获得大量天然气成为大气田. 腐泥 型烃源岩在热演化中期有相当长时间是形成石油为 主的“生油窗”, 而为“中断型气源岩”, 故相对在地史 上不能长期的充足向致密砂岩供气, 因此, 油型气成 
为致密砂岩的气源比煤成气的逊色得多. 中国除致 密砂岩大气田气源均为煤成气外, 还有许多致密砂 岩中, 小型气田的气源也是煤成气, 例如中坝气田须 二段 $\left(\mathrm{T}_{3} x^{2}\right)$ 气藏, 孝泉气藏, 户部寨气藏(耿玉臣, 1993；许化政, 1991；曾大乾等, 2003). 不仅在中国 煤成气成为大、中、小型致密砂岩气气田的气源, 在 北美煤成气也是致密砂岩的主流气源. 西加拿大盆 地西缘是著名深盆气区, 下白严统 Spirit River 组暗 色泥岩, 页岩夹煤层, 有机质以腐殖型为主, TOC 平 均在 $2 \%$ 以上, 是煤成气的源岩, 该组中 Father A 段, Peace River 组 Cadotte 段致密砂岩是深盆气的主要气 层, 在该盆地气田内发现了 Elmworth 气田, Edson 气 田, Hoadley 气田和 Simonette 气田等一批致密砂岩气 田(Masters, 1984). Edson 气田的烷烃气 $\delta^{13} \mathrm{C}_{1}, \delta^{13} \mathrm{C}_{2}$, $\delta^{13} \mathrm{C}_{3}, \delta^{13} \mathrm{C}_{\mathrm{i} 4}$ 和 $\delta^{13} \mathrm{C}_{\mathrm{n} 4}$ 值分别为 $-37.3 \%,-23.59 \%$, $-23.29 \%,-22.42 \%$ 和 $-22.42 \%$; Simonette 气田的烷烃 气 $\delta^{13} \mathrm{C}_{1}, \delta^{13} \mathrm{C}_{2}, \delta^{13} \mathrm{C}_{3}, \delta^{13} \mathrm{C}_{\mathrm{i} 4}$ 和 $\delta^{13} \mathrm{C}_{\mathrm{n} 4}$ 值分别为 $-39.22 \%$ o, $-24.77 \%$ o, $-22.25 \%$ o, - $22.41 \%$ o和 $-22.23 \%$ 。 (James, 1990), 均具有煤成气的特征(图 2, 3). 美国落 基山盆地群中众多深盆气(致密砂岩气)主要气源来 自白严系煤层和煤系有机碳含量丰富的III型干酪根 泥质岩(张金亮和常象春, 2002; 童晓光等, 2012). Law(1984)认为大绿河盆地深盆气的气源来自上白严 统 Lance, Almond 和 Rock Springs 组的煤层和腐殖型 的碳质页岩. 圣胡安盆地深盆气的气源主要来自上 白严统 Mesaverde 和 Fruitland 组中暗色泥页岩和广泛 夹的煤层(Law, 1992). 目前中国发现的致密砂岩气 的气源均来自煤系烃源岩, 北美科迪勒拉山和落基 山脉东部的致密砂岩深盆气的气源也来自煤系烃源 岩, 但不排除少数致密砂岩气的气源可以来自腐泥 型烃源岩的油型气, 例如, 阿巴拉契亚盆地北部深盆 气(Burruss 和 Laughrey, 2010).

\section{2 原生烷烃气碳同位素值随分子碳数顺序递增}

原生的未受次生改造的烷烃气, 碳同位素值随 烷烃气分子碳数顺序递增, $\delta^{13} \mathrm{C}$ 值依次递增称正碳同 位素系列, 即 $\delta^{13} \mathrm{C}_{1}<\delta^{13} \mathrm{C}_{2}<\delta^{13} \mathrm{C}_{3}<\delta^{13} \mathrm{C}_{4}$ (Dai 等, 2004). 烷烃气正碳同位素系列在国内外含油气盆地天然气 中普遍存在(戴金星等, 1992; Dai 等, 2005a; Chen 等, 2000; Boreham 和 Edwards, 2008; Ni 等, 2011). 根据 表 2 鄂尔多斯盆地和四川盆地具有正碳同位素系列 的气样值编了图 7(a)和(b). 从图 7 可见各盆地的正碳 同位素系列, 其 $\delta^{13} \mathrm{C}_{1}, \delta^{13} \mathrm{C}_{2}, \delta^{13} \mathrm{C}_{3}$ 和 $\delta^{13} \mathrm{C}_{4}$ 的最重值 连线 (A D ), 最轻值连线 $\left(\mathrm{A}^{\prime} \sim \mathrm{D}^{\prime}\right)$ 和平均值连线均具有 随烷烃气碳数分子增加而递重的规律. 表 3 为鄂尔多 斯盆地和四川盆地 $\delta^{13} \mathrm{C}_{1}, \delta^{13} \mathrm{C}_{2}, \delta^{13} \mathrm{C}_{3}$ 和 $\delta^{13} \mathrm{C}_{4}$ 正碳
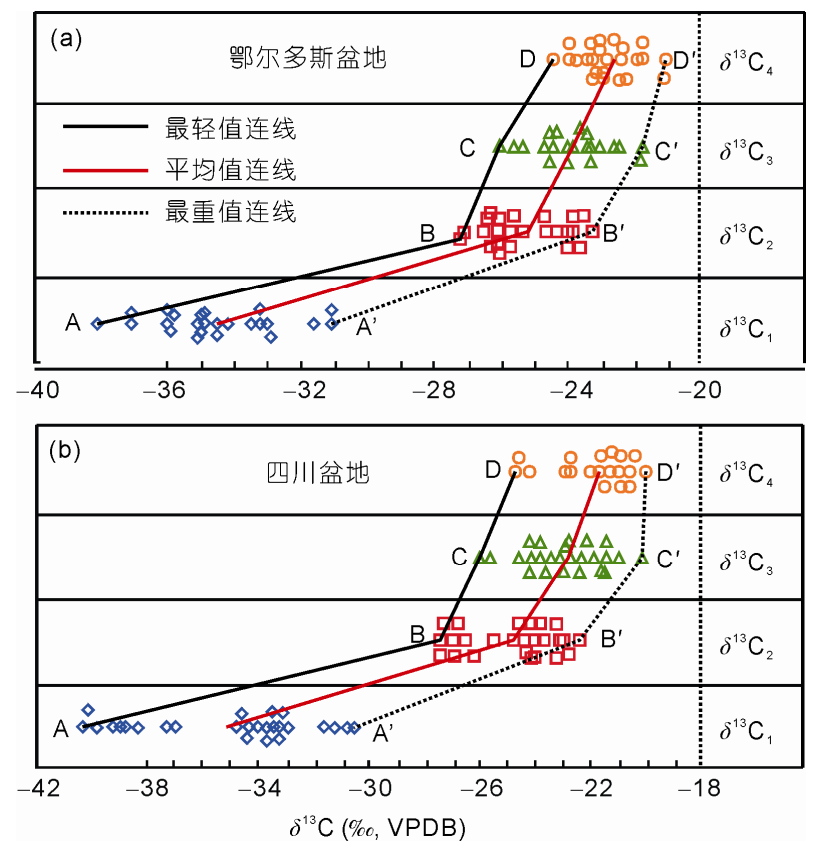

图 7 鄂尔多斯盆地(a)和四川盆地(b)致密砂岩烷烃气碳同 位素分布以及最重值、最轻值和平均值连线

表 3 鄂尔多斯盆地和四川盆地正碳同位素系列的最大值、最小值和平均值

\begin{tabular}{|c|c|c|c|c|c|c|c|c|c|}
\hline 盆地 & & $\begin{array}{c}\delta^{13} \mathrm{C}_{1}(\% o \\
\mathrm{VPDB})\end{array}$ & 井号 & $\begin{array}{c}\delta^{13} \mathrm{C}_{2}(\% o \\
\mathrm{VPDB})\end{array}$ & 井号 & $\begin{array}{c}\delta^{13} \mathrm{C}_{3}(\% o \\
\mathrm{VPDB})\end{array}$ & 井号 & $\delta^{13} \mathrm{C}_{4}(\% \circ, \mathrm{VPDB})$ & 井号 \\
\hline \multirow{3}{*}{$\begin{array}{c}\text { 鄂尔多斯 } \\
\text { 盆地 }\end{array}$} & 最大值 & -31.1 & 洲 22-8 & -23.2 & 米 37-13 & -21.7 & 洲 16-9 & -21.0 & 洲 1 \\
\hline & 最小值 & -38.1 & D22 & -27.2 & DK17 & -26.0 & D16 & -24.4 & 苏 76 \\
\hline & 平均值 & -34.5 & & -25.2 & & -23.8 & & -22.7 & \\
\hline \multirow{3}{*}{ 四川盆地 } & 最大值 & -30.5 & 邛西 14 & -22.4 & 邛西 006-x1 & -20.1 & CX480-1 & -20.0 & CX480-1, 新 882 \\
\hline & 最小值 & -40.3 & 角 48 & -27.4 & 广安 56 ; 角 33 & -26.0 & 广安 56 & -24.7 & 广安 002-39 \\
\hline & 平均值 & -35.1 & & -24.8 & & -22.9 & & -21.8 & \\
\hline
\end{tabular}


同位素系列最大值、最小值和平均值的井号及 $\delta^{13} \mathrm{C}$ 值. 由于中国致密砂岩大气田天然气都是煤成气, 表 3 的 $\delta^{13} \mathrm{C}_{1}$ 分布范围从-30.5\% - $40.3 \%$, 也是煤成气 $\delta^{13} \mathrm{C}_{1}$ 分布数值域. Patience(2003)认为煤成气的 $\delta^{13} \mathrm{C}_{1}$ 值分布在-22\% - 38\% , 中国的 $\delta^{13} \mathrm{C}_{1}$ 最轻值和最重 值比 Patience 报道的都轻.

\section{3 重烃气与甲烷碳同位素的差值随源岩成熟度 增加而渐减}

对于有机成因的烷烃气，随着源岩成熟度的增 加, 干燥系数 $\left(\mathrm{C}_{1} / \mathrm{C}_{1 \sim 4}\right)$ 也逐渐增大 (Stahl, 1979; Prinzhofer 等, 2000). 中国致密砂岩大气田煤成气的 重烃气与甲烷碳同位素的差值, 有随源岩成熟度增 加而渐减的特征. 煤成气的 $R_{\mathrm{o}}$ 值可以利用 $\delta^{13} \mathrm{C}_{1}=14.12 \lg R_{\mathrm{o}}-34.39$ (戴金星和戚厚发, 1989)求得. 图 8(a) 和 (c) 表明鄂尔多斯盆地和四川盆地具有 $\delta^{13} \mathrm{C}_{2}-\delta^{13} \mathrm{C}_{1}$ 及 $\delta^{13} \mathrm{C}_{3}-\delta^{13} \mathrm{C}_{1}$ 差值随着源岩 $R_{\mathrm{o}}$ 增大而渐减 的特征. 同时重烃气与甲烷碳同位素的差值, 也有随 $\mathrm{C}_{1} / \mathrm{C}_{1 \sim 4}$ 值增大而渐减的特征(图 8(b)和(d)).

\section{4 烷烃气稳定碳同位素倒转的成因}

当烷烃气的 $\delta^{13} \mathrm{C}$ 值不按分子碳数顺序递增或递 减, 即排列出现混乱时, 称为碳同位素倒转, 例如: $\delta^{13} \mathrm{C}_{1}>\delta^{13} \mathrm{C}_{2}<\delta^{13} \mathrm{C}_{3}<\delta^{13} \mathrm{C}_{4}$ 或 $\delta^{13} \mathrm{C}_{1}<\delta^{13} \mathrm{C}_{2}>\delta^{13} \mathrm{C}_{3}<\delta^{13} \mathrm{C}_{4}$ 等. 表 2 中 81 个气样中有 31 个发生碳同位素倒转, 倒转 率为 $38 \%$. 值得注意的是, 中国 15 个致密砂岩大气 田, 多数气田(榆林、子洲、大牛地、米脂、神木、新 场、广安、八角场和邛西)碳同位素没有发生倒转, 而 苏里格气田、合川气田、安岳气田和大北气田多口井 烷烃气碳同位素倒转, 乌审旗气田和洛带气田仅个 别井出现碳同位素倒转. 苏里格气田 18 个气样中 14 个出现碳同位素倒转(表 2), 倒转率高达 $78 \%$.

由表 2 和图 9 可知, 在倒转的 31 个样品中以 $\delta^{13} \mathrm{C}_{4}$ 值变轻即 $\delta^{13} \mathrm{C}_{3}>\delta^{13} \mathrm{C}_{4}$ 占首位的有 19 个, 四川盆 地合川气田、安岳气田、洛带气田和塔里木盆地大北 气田均属此类倒转, 倒转值 $0.1 \%$ o(龙 42) 2.7\%o(潼南 104 ), 一般为 $0.8 \%$ 以上, 四川盆地此类倒转明显(图 $9)$; 倒转占第 2 位为 $\delta^{13} \mathrm{C}_{3}$ 变轻即 $\delta^{13} \mathrm{C}_{2}>\delta^{13} \mathrm{C}_{3}$, 倒转值 为 $0.1 \%$ 。 (苏 95) 1.6\%o(苏 139, 苏 48-15-68), 一般为 $0.9 \%$ 以上; 倒转占第 3 位为 $\delta^{13} \mathrm{C}_{2}$ 变重, 倒转值为 0.2\%o(苏 77-6-8) 2.3\%o(苏 120-52-82), 一般在 0.6\%。以 上. 后两种倒转仅出现在鄂尔多斯盆地, 主要在苏里 格气田(图 10). 前人认为 $\delta^{13} \mathrm{C}_{3}>\delta^{13} \mathrm{C}_{4}$ 相当普遍(Fuex, 1977), 而 $\delta^{13} \mathrm{C}_{2}>\delta^{13} \mathrm{C}_{3}$ 则很少见(Erdman 和 Morris, 1974; Fuex, 1977). 本文研究也说明 $\delta^{13} \mathrm{C}_{3}>\delta^{13} \mathrm{C}_{4}$ 倒转 是普遍占首位的, 同时也指出 $\delta^{13} \mathrm{C}_{2}>\delta^{13} \mathrm{C}_{3}$ 并不是很
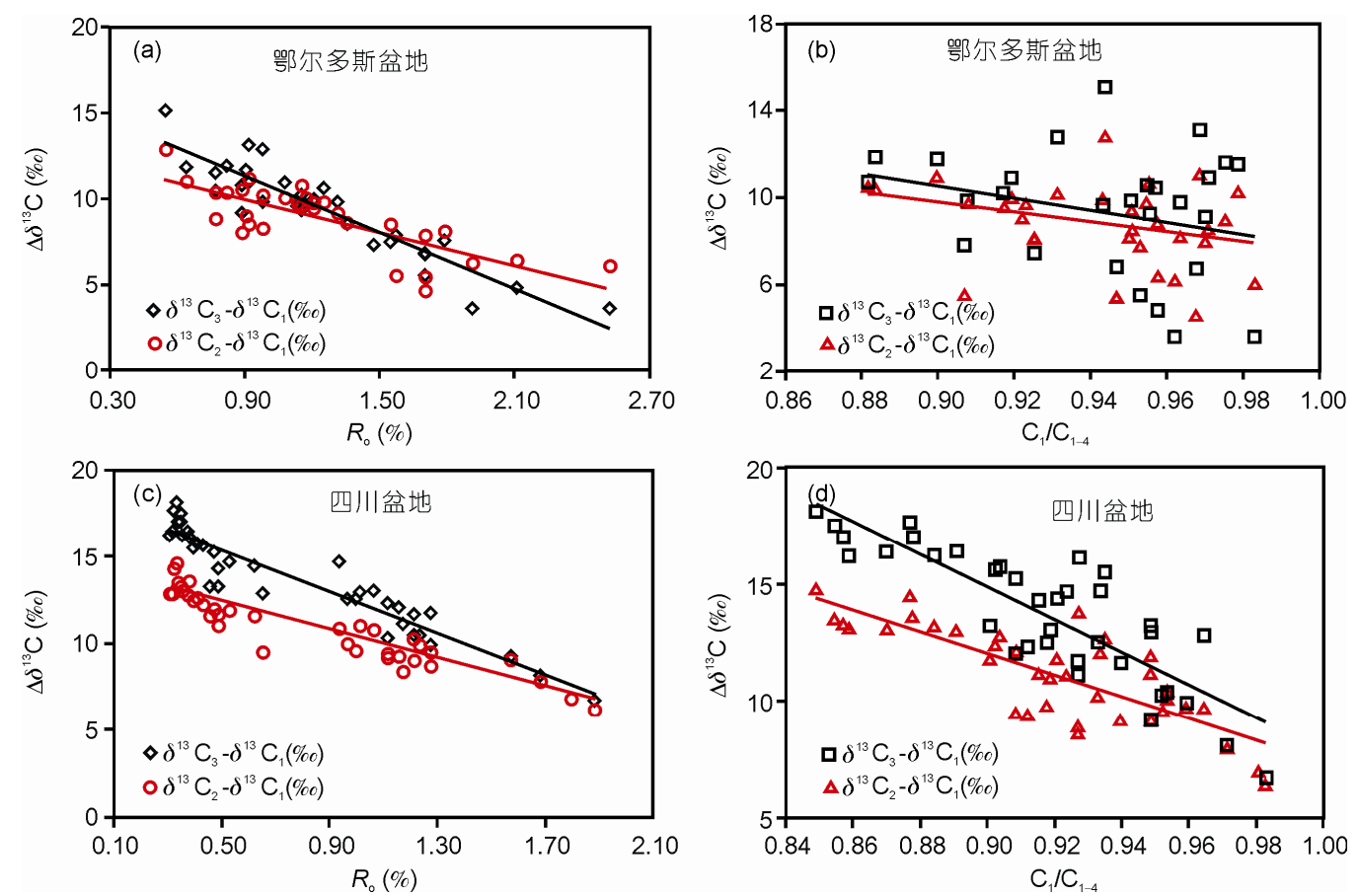

图 8 鄂尔多斯盆地和四川盆地致密砂岩气烷烃气重烃气与甲烷碳同位素之差值、 $R_{0}$ 和 $\mathrm{C}_{1} / \mathrm{C}_{1 \sim 4}$ 关系图 


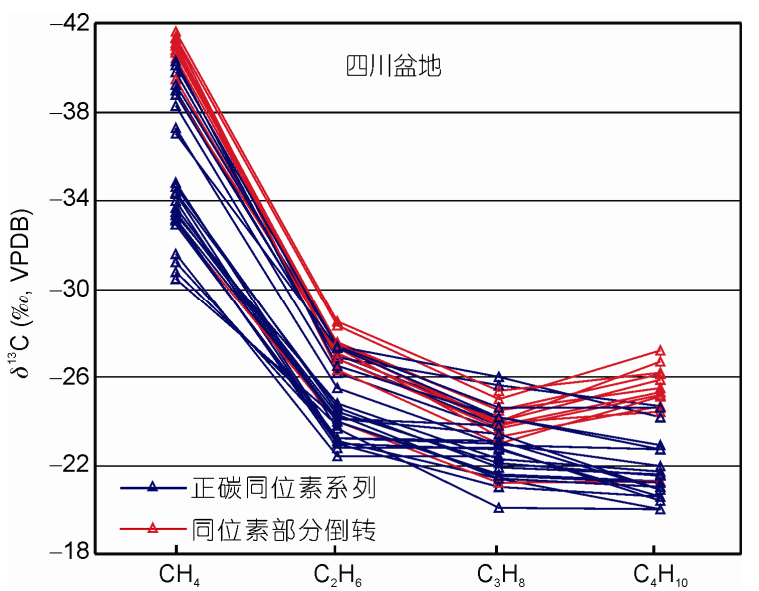

图 9 四川盆地致密砂岩大气田烷烃气稳定碳同位素连线

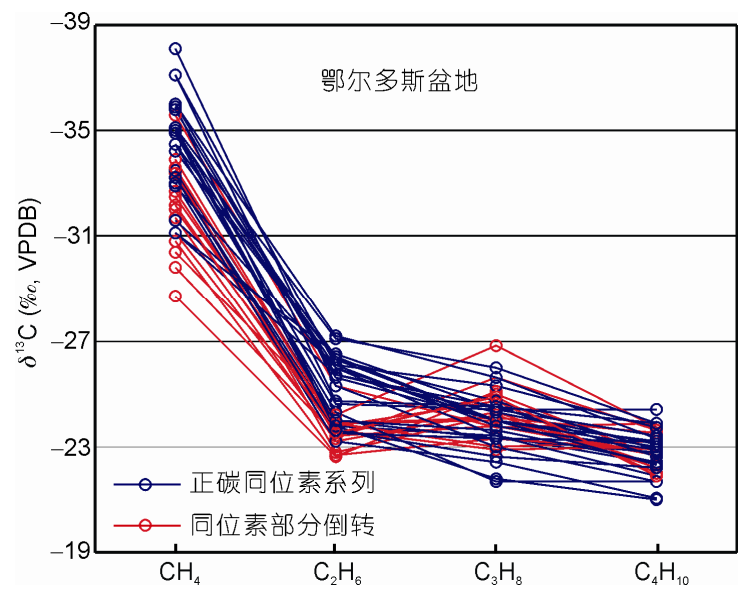

图 10 鄂尔多斯盆地致密砂岩大气田烷烃气稳定碳同位素 连线

\section{少见, 在苏里格气田还成为倒转的主流.}

烷烃气碳同位素倒转的成因有以下几种: (1) 有 机烷烃气和无机烷烃气的混合; (2) 煤成气和油型气 的混合; (3) 同型不同源气或同源不同期气的混合; (4) 天然气的某一或某些组分被细菌氧化(Dai 等, 2004); (5) 气层气和水溶气的混合 (Qin, 2012); (6) 硫酸盐热 还原反应(TSR)(刘全有等, 2007; Hao 等, 2008); (7)
氧化还原反应过程中的瑞利分馏作用 (Burruss 和 Laughrey, 2010).

利用与烷烃气伴生的氦同位素的 $R / R a$ 值可作为 旁证烷烃气是有机成因或无机成因的指标. 一般认 为与壳源氦伴生的烷烃气是有机成因烷烃气, 与幔 源氦伴生的烷烃气可能是无机成因烷烃气，通常认 为壳源氦的 $R / R a$ 值为 $0.01 \sim 0.1$ (Jenden 等, 1993; 王先 涁, 1989; 徐永昌, 1998), Poreda 等(1986)认为壳源氦 ${ }^{3} \mathrm{He} /{ }^{4} \mathrm{He}$ 值为 $2 \times 10^{-8} \sim 3 \times 10^{-8}$, 即 $R / R a$ 为 $0.014 \sim 0.021$. 四川盆地 57 个气样的 ${ }^{3} \mathrm{He} /{ }^{4} \mathrm{He}$ 分布在 $0.40 \times 10^{-8}$ $4.86 \times 10^{-8}$, 平均为 $1.89 \times 10^{-8}$, 塔里木盆地 32 个气样 的 ${ }^{3} \mathrm{He} /{ }^{4} \mathrm{He}$ 分布在 $2.09 \times 10^{-8} \sim 23.5 \times 10^{-8}$, 平均 $6.07 \times$ $10^{-8}$ (Dai 等, 2000); 鄂尔多斯盆地 46 个气样的 ${ }^{3} \mathrm{He} /{ }^{4} \mathrm{He}$ 分布在 $3.1 \times 10^{-8} \sim 1.2 \times 10^{-7}$, 平均 $4.36 \times 10^{-8}$, $R / R a$ 值为 $0.022 \sim 0.085$ (戴金星等, 2005). 由此可见, 致密砂岩大气田所在的鄂尔多斯盆地, 四川盆地和 塔里木盆地 $R / R a$ 均具壳源气的特征. 并且一些倒转 气井的氦同位素(表 4)也是壳源型, 由此得出发生碳 同位素倒转井的烷烃气均为有机成因烷烃气. 由表 2 可见烷烃气大部分是正碳同位素系列, 具有机成因 气的特征，没有发现无机成因烷烃气的负碳同位素 系列 $\left(\delta^{13} \mathrm{C}_{1}>\delta^{13} \mathrm{C}_{2}>\delta^{13} \mathrm{C}_{3}>\delta^{13} \mathrm{C}_{4}\right.$ ) (Des Marais 等, 1981; 戴金星, 1992; Dai 等, 2005b; Hosgörmez, 2007). 以上 两方面说明碳同位素倒转不是有机成因气和无机成 因气混合所致.

天然气烷烃气的某一或某些组分被细菌氧化致 使的倒转, 往往某组分含量降低(Dai 等, 2004). 但从 表 2 可知, 所有倒转的某组分含量并没有降低; 同时 细菌一般在 $80^{\circ} \mathrm{C}$ 以下繁殖, 由于普遍出现倒转的苏 里格气田所有倒转的井气层埋深均大于 $3321 \mathrm{~m}$, 气 层地温高于 $80^{\circ} \mathrm{C}$, 故倒转并不是细菌氧化某烷烃气 组分造成的.

由图 9 及上述行文可知，四川盆地产于须家河组 和上覆杂色地层蓬莱镇组 $\left(\mathrm{J}_{2} p\right)$, 遂宁组 $\left(\mathrm{J}_{2} S n\right)$ 和上沙

表 4 有关碳同位素倒转井的氦同位素

\begin{tabular}{|c|c|c|c|c|c|}
\hline \multirow{2}{*}{ 井号 } & \multicolumn{2}{|c|}{ 氦同位素 } & \multirow{2}{*}{ 井号 } & \multicolumn{2}{|c|}{ 氦同位素 } \\
\hline & ${ }^{3} \mathrm{He} /{ }^{4} \mathrm{He}\left(\times 10^{-8}\right)$ & $\mathrm{R} / \mathrm{Ra}$ & & ${ }^{3} \mathrm{He} /{ }^{4} \mathrm{He}\left(\times 10^{-8}\right)$ & $\mathrm{R} / \mathrm{Ra}$ \\
\hline 苏 21 & $4.478 \pm 0.34$ & 0.032 & 岳 105 & $2.124 \pm 0.26$ & 0.015 \\
\hline 苏 139 & $9.171 \pm 0.48$ & 0.066 & 大北 102 & $5.962 \pm 0.65$ & 0.043 \\
\hline 苏 48-2-86 & $5.650 \pm 0.36$ & 0.040 & 大北 103 & $5.037 \pm 0.63$ & 0.036 \\
\hline 苏 77-2-5 & $4.190 \pm 0.27$ & 0.030 & 大北 201 & $6.505 \pm 0.27$ & 0.046 \\
\hline 苏 77-6-8 & $4.687 \pm 0.30$ & 0.033 & 大北 202 & $6.507 \pm 0.37$ & 0.046 \\
\hline
\end{tabular}


溪庙组 $\left(\mathrm{J}_{2} s\right)$ 的天然气, 尽管有须一段 $\left(\mathrm{T}_{3} x^{1}\right)$ 和自流井 组 $\left(\mathrm{J}_{2} z\right)$ II 型烃源岩形成少许油型伴生气, 但图 2, 图 3 和图 9 中 $\delta^{13} \mathrm{C}_{1 \sim 4}$ 值均具煤成气性质, 说明四川盆地致 密砂岩大气田烷烃气碳同位素倒转不是煤成气和油 型气混合造成. 由图 5 和上述行文可知, 鄂尔多斯盆 地杂色地层的上石盒子组 $\left(\mathrm{P}_{2} s h\right)$ 和下石盒子组 $\left(\mathrm{P}_{2} x\right)$ 非 烃源岩, 而山西组 $\left(\mathrm{P}_{1} s\right)$, 太原组 $\left(\mathrm{P}_{1} t\right)$ 和本溪组 $\left(\mathrm{C}_{2} b\right)$ 是 主要煤成气源岩, 但太原组和本溪组石灰岩是油型 气源岩, 并在石灰岩源岩发育的靖边气田马家沟组 $\left(\mathrm{O}_{1} m\right)$ 储层中发现少量油型气, 并致使出现煤成气和 油型气混合的烷烃气碳同位素倒转(夏新宇, 2000; Dai 等, 2005a). 但从图 2, 图 3 和图 10 中 $\delta^{13} \mathrm{C}_{1 \sim 4}$ 值均 具煤成气性质, 说明鄂尔多斯盆地苏里格气田出现 大量的碳同位素倒转和乌审旗气田出现的个别碳同 位素倒转, 不是煤成气和油型气相混合的结果.

许多学者利用包裹体、生烃史模拟、古地温史、 地层埋藏史和甲烷碳同位素动力学的综合分析, 得 出苏里格气田和乌审旗气田具有多期充注和成藏. 但各家确定成藏期次多少不一: 6 期充注-成藏(刘建 章等, 2005), 3 期充注-成藏(丁超等, 2011, 刘新社等, 2007)和 2 期充注-成藏(李贤庆等, 2012; 薛会等, 2009; 张文忠等, 2009). 尽管各学者充注-成藏期 2, 3, 6 期 不一, 但都认为 168 156 或 190 154 Ma 和 148 143 或 137 96 Ma 是两个主要充注-成藏期. 由此可以确 定苏里格气田和乌审旗气田烷烃气碳同位素倒转, 是由煤成气不同充注-成藏期气的混合造成的. 苏里 格气田碳同位素倒转率高达 $78 \%$, 是与多次充注-成

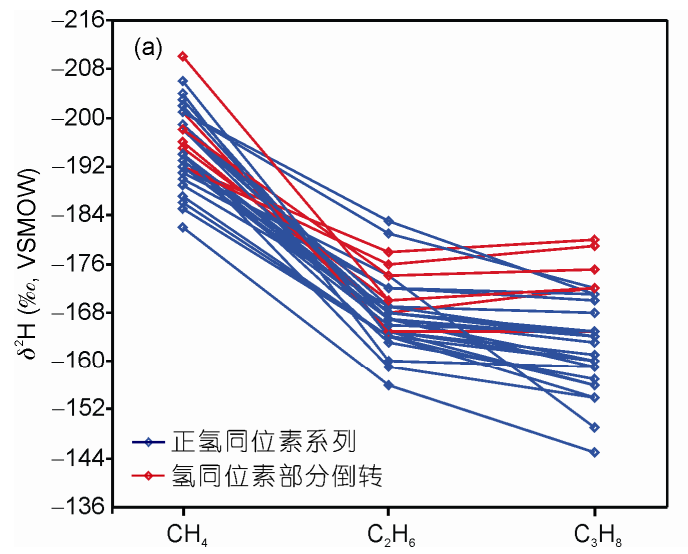

藏有关. 四川盆地合川气田和安岳气田烷烃气碳同 位素倒转, 是侏罗纪末和白严纪末两期充注-成藏的 煤成气混合所致(Zhao 等, 2010). 塔里木盆地大北气 田在 $5 \mathrm{Ma}$ 充注大量煤成气, 在 3 1 Ma 充注少量煤成 气相混合而导致烷烃气碳同位素倒转(朱忠谦等, 2011). 由上可见, 中国致密砂岩大气田烷烃气的碳 同位素倒转是不同期充注-成藏所致.

\section{4 烷烃气稳定氢同位素组成特征}

表 2 为中国 15 个致密砂岩大气田 73 个气样烷 烃气稳定氢同位素 $\delta^{2} \mathrm{H}_{1 \sim 3}$ 分析成果, 由表 2 可得如下 特征.

\section{1 原生烷烃气随分子中碳数增加氢同位素值递增}

原生的未发生次生改造的烷烃气随着分子中碳 数递增氢同位素值而逐渐变重, 称正氢同位素系列, 即 $\delta \mathrm{D}_{1}<\delta \mathrm{D}_{2}<\delta \mathrm{D}_{3}$. 烷烃气正氢同位素系列在国内外含 油气盆地中普遍存在(Barker 和 Pollock, 1984; 戴金 星等, 1992; Dai 等, 2012b; Laughrey 和 Baldassare, 1998; 刘全有等, 2007; Burruss 和 Laughrey, 2010). 鄂尔多斯盆地和四川盆地致密砂岩大气田烷烃气的 氢同位素系列绝大部分呈现正氢同位素系列, 从图 11 可见两盆地致密砂岩大气田烷烃气呈正氢同位素 系列. 根据表 2 中氢同位素值编制图 12, 该图中烷烃 气最轻氢同位素值连线 A-B-C, 最重氢同位素值连线 $\mathrm{A}^{\prime}-\mathrm{B}^{\prime}-\mathrm{C}^{\prime}$ 以及平均值连线均呈现随分子中碳数增加而 逐渐变重的规律.

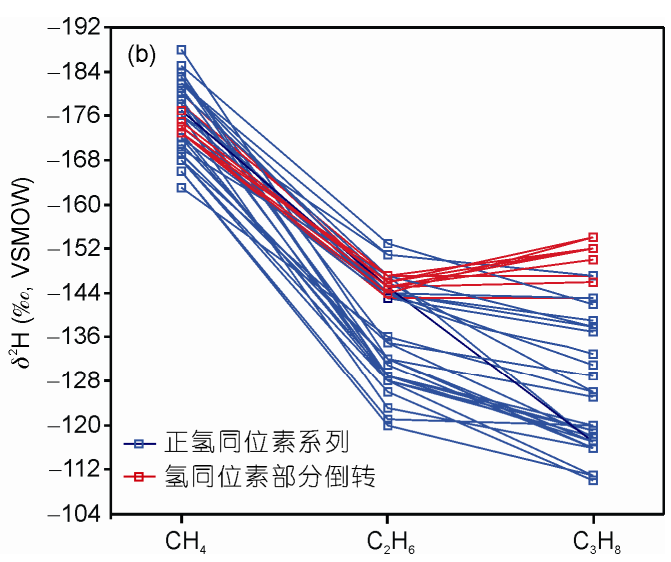

图 11 中国致密砂岩大气田烷烃气稳定氢同位素连线

(a) 鄂尔多斯盆地; (b) 四川盆地 

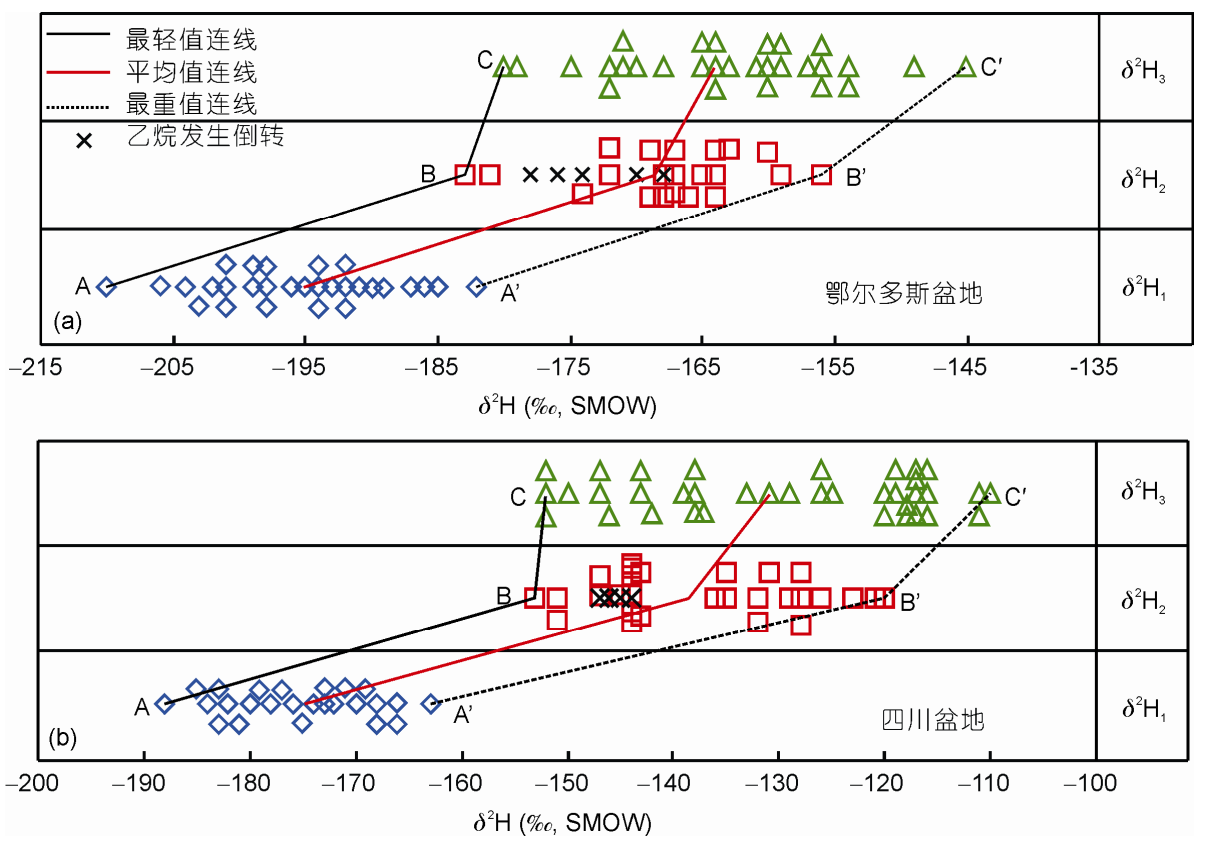

图 12 鄂尔多斯盆地(a)和四川盆地(b)致密砂岩大气田烷烃气氢同位素分布和烷烃气氢同位素最轻、最重及平均值
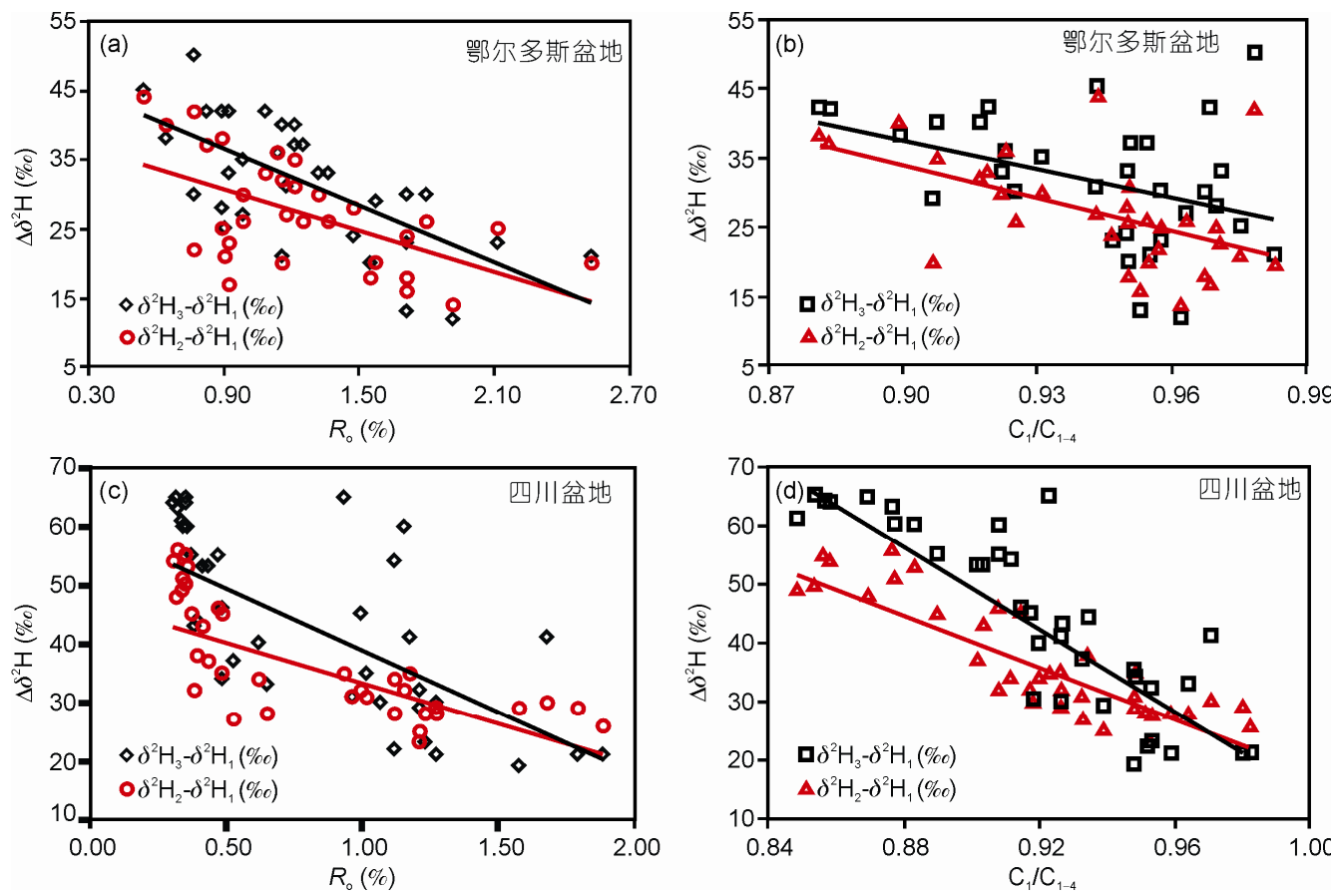

图 13 中国鄂尔多斯盆地和四川盆地致密砂岩气重烃气与甲烷氢同位素差值和 $R_{0}-\mathrm{C}_{1} / \mathrm{C}_{1 \sim 4}$ 关系图

4.2 重烃气与甲烷稳定氢同位素的差值随成熟度 增加而逐渐减小

对于有机热成因的烷烃气，随着成熟度的增加， 干燥系数也会逐渐增大 (Stahl, 1977; Prinzhofer 等,
$2000)$. 利用中国煤成气 $\delta^{13} \mathrm{C}_{1}=14.12 \lg R_{\mathrm{o}}-34.39$ 关系 式(戴金星和戚厚发, 1989), 计算了鄂尔多斯盆地和 四川盆地致密砂岩气(表 2)的烃源岩成熟度. 中国致 密砂岩气烷烃气重烃气与甲烷氢同位素之差值随着 
成熟度(干燥系数)的增加呈现逐渐减小的趋势(图 13). 另外, 鄂尔多斯盆地二叠系致密砂岩气的源岩成熟度 明显比四川盆地三叠系以及侏罗系致密砂岩气的高, 而鄂尔多斯盆地致密砂岩气的重烃气与甲烷氢同位素 的差值要小于四川盆地, 表明天然气生成过程中, 越 到后期，重烃气与甲烷氢同位素值越趋向一致.

\section{3 烷烃气稳定氢同位素倒转的成因}

由表 2 可知鄂尔多斯盆地和四川盆地致密砂岩 大气田 73 个氢同位素系列样品中仅有 13 个发生倒转, 倒转率为 $17.8 \%$, 明显低于碳同位素倒转率, 且均表 现为乙烷氢同位素值相对于丙烷偏重, 即 $\delta^{2} \mathrm{H}_{2}>\delta^{2} \mathrm{H}_{3}$ (图 11). 鄂尔多斯盆地致密砂岩气 $\delta^{2} \mathrm{H}_{2}>\delta^{2} \mathrm{H}_{3}$ 倒转幅 度为 1\%o(洲 22-18) 4\%o(苏 14-0-31), 而四川盆地的倒 转幅度较大, 为 $1 \%$ o(广安 002-39) 10\%o(邛西 006-X1). 中国 15 个致密砂岩大气田中大部分气田的烷烃气表 现为正氢同位素系列, 仅有少部分气田发生倒转, 如 苏里格气田、子洲气田、新场气田、广安气田、洛带 气田和邛西气田, 其中苏里格气田和邛西气田发生 氢同位素倒转的比例最大.

烷烃气氢同位素倒转在世界多个地区广泛发现, 不同的学者对其原因进行了探讨(戴金星, 1990; 刘 全有等, 2007; Burruss 和 Laughrey, 2010). 烷烃气受 到细菌氧化以及煤成气和油型气的混合是造成氢同 位素倒转的两个重要原因(戴金星, 1990). Kinnaman 等(2007)定量研究了海洋沉积物中细菌氧化对甲烷, 乙烷以及丙烷氢同位素的分馏效应, 天然气中不同 组分对于抗生物降解的能力不同, 丙烷和正丁烷最 容易遭到生物降解, 剩余天然气组分碳, 氢同位素会 逐渐变重. Liu 等(2008)研究塔里木盆地天然气氢同
位素组成时, 认为硫酸盐热还原反应(例如, TSR)会 造成油型气的甲烷和乙烷氢同位素发生倒转(例如 $\delta^{2} \mathrm{H}_{1}>\delta^{2} \mathrm{H}_{2}$ ). Burruss 等(2010)研究 Appalachian 盆地奥 陶系和志留系储层深盆气时, 发现甲烷和乙烷氢同 位素之间存在倒转现象, 他们认为这是由于原生天 然气与在高温条件下与水介质发生反应的高成熟甲 烷混合所造成. 中国致密砂岩气烷烃气未发生细菌 氧化, 并且中国致密砂岩气均是煤成气, 前文分析造 成碳同位素倒转的原因是同源不同期煤成气的混合, 因此造成氢同位素倒转的原因也是不同期煤成气的 混合. 苏里格气田烷烃气碳, 氢同位素均表现出较高 的倒转率, 这与其多期成藏充注有着密切联系.

\section{5 结论}

2010 年底中国致密砂岩大气田的年产量和储量 分别为 $222.5 \times 10^{8} \mathrm{~m}^{3}$ 和 $28657 \times 10^{8} \mathrm{~m}^{3}$, 分别占中国年 产量和储量的 $23.5 \%$ 和 $37.3 \%$, 是中国非常规气中的 最高者和最多者, 对中国天然气工业快速发展起重 要作用.

中国致密砂岩大气田烷烃气的稳定碳，氢同位 素组成特征是: (1) 综合 $\delta^{13} \mathrm{C}_{1}-\delta^{13} \mathrm{C}_{2}-\delta^{13} \mathrm{C}_{3}$ 图版, $\delta^{13} \mathrm{C}_{1}$ $\delta^{13} \mathrm{C}_{1} / \mathrm{C}_{2 \sim 3}$ 图版和 $\delta^{13} \mathrm{C}_{1}$ 与 $\delta^{13} \mathrm{C}_{2}$ 关系对比确定, 中国致 密砂岩大气田的气源是煤成气; (2) 原生烷烃气随分 子中碳数递增, 其碳同位素值和氢同位素值也随之 递重，即 $\delta^{13} \mathrm{C}_{1}<\delta^{13} \mathrm{C}_{2}<\delta^{13} \mathrm{C}_{3}<\delta^{13} \mathrm{C}_{4}$ 和 $\delta^{2} \mathrm{H}_{1}<\delta^{2} \mathrm{H}_{2}<\delta^{2} \mathrm{H}_{3}$; (3) 碳氢同位素倒转的成因多达 6 种, 中国致密砂岩 大气田碳氢同位素倒转主要是多期成藏充注所致; (4) $\delta^{13} \mathrm{C}_{2}-\delta^{13} \mathrm{C}_{1}, \delta^{13} \mathrm{C}_{3}-\delta^{13} \mathrm{C}_{1}$ 随 $R_{0}(\%)$ 和 $\mathrm{C}_{1} / \mathrm{C}_{1 \sim 4}$ 的增大 而减小.

致谢张文正教授在鄂尔多斯盆地气样采集时给予协助; 中国石油勘探开发研究院廊坊分院马新华和李谨高级工 程师对碳氢同位素测试给予支持，审稿人为本文提供了宝贵的修改意见，在此深表感谢.

\section{参考文献}

戴金星. 1980. 我国煤系含气性的初步研究. 石油学报, 1:27-37

戴金星. 1990. 我国有机烷烃气的氢同位素的若干特征. 石油勘探与开发, 5: 27-32

戴金星. 1992. 各类烷烃气的鉴别. 中国科学 B 辑, 22: 183-195

戴金星, 戚厚发. 1989. 我国煤成烃气的 $\delta^{13} \mathrm{C}-R_{\mathrm{o}}$ 关系. 科学通报, 34: 690-692

戴金星, 裴锡古, 戚厚发. 1992. 中国天然气地质学(卷一). 北京: 石油工业出版社. 35-60

戴金星, 钟宁宁, 刘德汉, 等. 2000. 中国煤成大中型气田地质基础和主控因素. 北京: 石油工业出版社. 180-182

戴金星, 李剑, 侯路. 2005. 鄂尔多斯盆地氦同位素的特征. 高校地质学报, 11: 473-478 
戴金星, 倪云燕, 黄士鹏, 等. 2014. 煤成气研究对中国天然气工业发展的重要意义. 天然气地球科学, 25: 1-22

丁超, 陈刚, 郭兰, 等. 2011. 鄂尔多斯盆地东北部上古生界油气成藏期次. 地质科技情报, 30: 69-73

耿玉臣. 1993. 孝泉构造侏罗系“次生气藏”的形成条件和富集规律. 石油实验地质, 15: 262-271

刘宝和. 2011. 中国油气田开发志(卷 13-1). 北京: 石油工业出版社. 753-768

刘建章, 陈红汉, 李剑, 等. 2005. 运用流体包裹体确定鄂尔多斯盆地上古生界油气成藏期次和时期. 地质科技情报, 24: 60-66

刘全有, 戴金星, 李剑, 等. 2007. 塔里木盆地天然气氢同位素地球化学与对热成熟度和沉积环境的指示意义. 中国科学 D 辑: 地球科学,

37: 1599-1608

刘新社, 周立发, 候云东. 2007. 运用流体包裹体研究鄂尔多斯盆地上古生界天然气成藏. 石油学报, 28: 37-42

李贤庆, 李剑, 王康东, 等. 2012. 苏里格低渗砂岩大气田天然气充注、运移及成藏特征. 地质科技情报, 31: 55-62

童晓光, 郭彬程, 李建忠, 等. 2012. 中美致密砂岩气成藏分布异同点比较研究与意义. 中国工程科学, 14: 9-15

王先涁. 1989. 稀有气体同位素地球化学和宇宙化学. 北京: 科学出版社. 112

许化政. 1991. 东兴凹陷致密砂岩气藏特征的研究. 石油学报, 12: 1-8

徐永昌, 沈平, 刘文汇, 等. 1998. 天然气中稀有气体地球化学. 北京: 科学出版社. 17-25

夏新宇. 2000. 碳酸盐岩生烃与长庆气田气源. 北京: 石油工业出版社. 2000

薛会, 王毅, 毛小平, 等. 2009. 鄂尔多斯盆地北部上古生界天然气成藏期次一一以杭锦旗探区为例. 天然气工业, 29: 9-12

杨俊杰, 裴锡古. 1996. 中国天然气地质学(卷四: 鄂尔多斯盆地). 北京: 石油工业出版社. 107-120

杨涛, 张国生, 梁坤, 等. 2012. 全球致密气勘探开发进展及中国发展趋势预测. 中国工程科学, 14: 64-68

杨华, 刘新社, 杨勇. 2012. 鄂尔多斯盆地致密气勘探开发形势与未来发展展望. 中国工程科学, 14: 40-48

翟光明主编. 1989. 中国石油地质志(卷 10). 北京: 石油工业出版社. 121-122

张士亚. 1994. 鄂尔多斯盆地天然气气源及勘探方向. 天然气工业, 14: 1-4

张金亮，常象春. 2002. 深盆气地质理论及应用. 北京: 地质出版社

曾大乾, 张世民, 卢立泽. 2003. 低渗透致密砂岩气藏裂缝类型及特征. 石油学报, 24: 36-39

邹才能, 陶士振, 袁选俊, 等. 2009. “连续型”油气藏及其在全球的重要性: 成藏、分布与评价. 石油勘探与开发, 36: 669-682

张文忠, 郭彦如, 汤达祯, 等. 2009. 苏里格气田上古生界储层流体包裹体特征及成藏期次划分. 石油学报, 30: 685-691

中国国家能源局. 2011. 中华人民共和国石油与天然气行业标准(SY/T6832-2011). 北京: 石油工业出版社

张国生，赵文智，杨涛，等. 2012. 我国致密砂岩气资源潜力、分布与未来发展地位. 中国工程科学, 14: 87-93

朱忠谦, 杨学君, 赵力涁, 等. 2011. 陆相湖盆致密砂岩储层裂缝形成机理研究一一塔里木盆地 $\mathrm{A}$ 气田巴什基奇克组为例. 见: 国际非 常规油气勘探开发(青岛)大会论文集. 北京: 地质出版社. 147-158

Baihly J, Grant D, Fan L, et al. 2007. Horizontal wells in tight gas sands: A method for risk management to maximize success. SPE Annual Technical Conference and Exhibition, Anaheim, California, U.S.A.

Barker J F, Pollock S J. 1984. The geochemistry and origin of natural gases in southern Ontario. Bull Canadian Petrol Geol, 32: 313-326

Boreham C J, Edwards D S. 2008. Abundance and carbon isotopic composition of neo-pentane in Australian natural gases. Org Geochem, 39 : $550-566$

Burruss R C, Laughrey C D. 2010. Carbon and hydrogen isotopic reversals in deep basin gas: Evidence for limits to the stability of hydrocarbons. Org Geochem, 41: 1285-1296

Chen J F, Xu Y C, Huang D F. 2000. Geochemistry characteristics and origin of natural gas in Tarim basin, China. AAPG Bull, 84: 591-606

Coplen T B, Brand W A, Gehre M, et al. 2006. New Guidelines for $\delta^{13} \mathrm{C}$ measurements. Anal Chem, 78: 2439-2441

Des Marais D J, Donchin J H, Nehring N L, et al. 1981. Molecular carbon isotope evidence for the origin of geothermal hydrocarbon. Nature, 292: 826-828

Dai J X, Song Y, Dai C S, et al. 2000. Conditions Governing the Formation of Abiogenic Gas and Gas Pools in Eastern China. Beijing and New York: Science Press. 65-66

Dai J X, Xia X Y, Qin S F, et al. 2004. Origins of partially reversed alkane $\delta^{13} \mathrm{C}$ values for biogenic gases in China. Org Geochem, 35: 405-411

Dai J X, Li J, Luo X, et al. 2005a. Stable carbon isotope compositions and source rock geochemistry of the giant gas accumulations in the Ordos Basin, China. Org Geochem, 36: 1617-1635

Dai J X, Yang S F, Chen H L, et al. 2005b. Geochemistry and occurrence of abiogenic gas accumulations in the Chinese sedimentary basins. Org Geochem, 36: 1664-1688

Dai J X, Ni Y Y, Wu X Q. 2012a. Tight gas in China and its significance in exploration and exploitation. Petrol Explor Dev, 39: 274-284

Dai J X, Ni Y Y, Zou C N. 2012b. Stable carbon and hydrogen isotopes of natural gases sourced from the Xujiahe Formation in the Sichuan Basin, China. Org Geochem, 43: 103-111

Dai J X, Xia X Y, Li Z S, et al. 2012c. Inter-laboratory calibration of natural gas round robins for $\delta^{2} \mathrm{H}$ and $\delta^{13} \mathrm{C}$ using off-line and on-line 
techniques. Chem Geol, 310-311: 49-55

Erdman J G, Morris D A. 1974. Geochemical correlation of petroleum. AAPG Bull, 58: 2326-2377

Elkins L E. 1978. The technology and economics of gas recovery from tight sands. SPE Production Technology Symposium

Fuex A A. 1977. The use of stable carbon isotopes in hydrocarbon exploration. J Geochem Explor, 7: 155-188

Holditch S A. 2006. Tight gas sands. J Petrol Technol, 58: 86-93

Hosgörmez H. 2007. Origin of the natural gas seep of Cirali (Chimera), Turkey: Site of the first Olympic fire. J Asian Earth Sci, 30: 131-141

Hao F, Guo T L, Zhu Y M, et al. 2008. Evidence for multiple stages of oil cracking and thermochemical sulfate reduction in the Puguang gas field, Sichuan Basin, China. AAPG Bull, 92: 611-637

Jenden P D, Kaplan I R, Poreda R, et al. 1988. Origin of nitrogen-rich natural gases in the California Great Valley: Evidence from helium, carbon and nitrogen isotope ratios. Geochim Cosmochim Acta, 52: 851-861

Jenden P D, Kaplan I R, Hilton D R, et al. 1993. Abiogenic hydrocarbons and mantle helium in oil and gas fields. The future of energy gases. US Geol Surv Professional Paper. 31-56

James A T. 1990. Correlation of reservoired gases using the carbon isotopic compositions of wet gas components. AAPG Bull, 74: 1441-1458

Kinnaman F S, Valentine D L, Tyler S C. 2007. Carbon and hydrogen isotope fractionation associated with the aerobic microbial oxidation of methane, ethane, propane and butane. Geochim Cosmochim Aeta, 71: 271-283

Law B E. 1984. Relationships of source rocks, thermal maturity and overpressuring to gas generation and occurrence in low permeability Upper Cretaceous and lower Tertiary rocks, Greater Green River basin, Wyoming, Colorado, and Utah. In: Woodward J, Meissner F F, Clayton J L, eds. Hydrocarbon Source Rocks of the Greater Rocky Mountain Region. Rocky Mountain Association of Geologists. 469-490

Law B E. 1992. Thermal maturity patterns of Cretaceous and Tertiary rock, San Juan Basin, Colorado and New Mexico. Geol Soc Am Bull, 104: 192-207

Laughrey C D, Baldassare F J. 1998. Geochemistry and origin of some natural gases in the plateau province, central Appalachian basin, Pennsylvania and Ohio. AAPG Bull, 82: 317-335

Masters J A. 1984. Lower Cretaceous oil and gas in Western Canada: Pressured "Elimworth-case study of a deep basin gas field". AAPG Memoir, 38: $1-33$

Ni Y Y, Ma Q S, Ellis G F, et al. 2011. Fundamental studies on kinetic isotope effect (KIE) of hydrogen isotope fractionation in natural gas systems. Geochim Cosmochim Acta, 75: 2696-2707

Poreda R J, Jenden P D, Kaplan E R. 1986. Mantle helium in Sacramento basin natural gas wells. Geochim Cosmochim Acta, 65: 3847-2853

Prinzhofer A, Mello M R, Takaki T. 2000. Geochemical characterization of natural gas: A physical multivariable approach and its applications in maturity and migration estimates. AAPG Bull, 84: 1152-1172

Patience R. 2003. Where did all the coal gas go? Org Geochem, 34: 375-387

Qin S F. 2012. Carbon isotopic composition of water-soluble gases and its geological significance in the Sichuan Basin. Petrol Explor Dev, 39: 335-342

Rooney M A, Claypool G E, Chung H M, et al. 1995. Modeling thermogenic gas generation using carbon isotope ratios of natural gas hydrocarbons. Chem Geol, 126: 219-232

Stahl W J. 1977. Carbon and nitrogen isotopes in hydrocarbon research and exploration. Chem Geol, 20: 121-149

Stahl W J. 1979. Geochemische Daten Nordwestdeutscher Oberkarbon, Zechtein-und Buntsandsteingase. Erdlöl Kohle Erdgal Petrochem, 32 : $65-70$

Spencer C W. 1985. Geologic aspects of tight gas reservoirs in the Rocky Mountain region. J Petrol Geol, 37: 1308-1314

Surdam R C. 1997. A new paradigm for gas exploration in anomalously pressured "tight gas sands" in the Rocky Mountain Laramide basins. In: Seals, traps, and the petroleum system. AAPG Memoir, 67: 283-298

U.S. Energy Information Adiministration. 2012. Annual energy outlook 2012. U.S. Energy Information Adiministration, Washington

Whiticar M J. 1999. Carbon and hydrogen isotope systematics of bacterial formation and oxidation of methane. Chem Geol, 161: 291-314

Yang H, Fu J H, Wei X S, et al. 2008. Sulige field in the Ordos Basin: Geological Setting, field discovery and tight gas reservoirs. Mar Pet Geol, 25: $387-400$

Zhang S C, Mi J K, Liu L P, et al. 2009. Geological features and formation of coal-formed tight sandstone gas pools in China: Cases from Upper Paleozoic gas pools, Ordos Basin (in Chinese). Petrol Explor Dev, 36: 320-330

Zhao W Z, Wang H J, Xu C C, et al. 2010. Reservoir-forming mechanism and enrichment conditions of extensive Xujiahe Formation gas reservoirs, central Sichuan Basin (in Chinese). Petrol Explor Dev, 37: 146-157

Zou C N, Jia J H, Tao S Z, et al. 2011. Analysis of Reservoir Forming Conditions and Prediction of Continuous Tight Gas Reservoirs for the Deep Jurassic in the Eastern Kuqa Depression, Tarim Basin. Acta Geol Sin, 85: 1173-1186 